Florida International University FIU Digital Commons

3-30-2012

\title{
Environmental and Cost impact Analysis of Materials and Assemblies in Building Construction
}

Deepika Nirmal

Florida International University, dnirm001@fiu.edu

DOI: $10.25148 /$ etd.FI12050249

Follow this and additional works at: https://digitalcommons.fiu.edu/etd

\section{Recommended Citation}

Nirmal, Deepika, "Environmental and Cost impact Analysis of Materials and Assemblies in Building Construction" (2012). FIU Electronic Theses and Dissertations. 643.

https://digitalcommons.fiu.edu/etd/643 


\title{
FLORIDA INTERNATIONAL UNIVERSITY
}

Miami, Florida

\section{ENVIRONMENTAL AND COST IMPACT ANALYSIS OF MATERIALS AND ASSEMBLIES IN BUILDING CONSTRUCTION}

\author{
A thesis submitted in partial fulfillment of the \\ requirements for the degree of \\ MASTER OF SCIENCE \\ in \\ CONSTRUCTION MANAGEMENT \\ by \\ Deepika Nirmal
}

2012 
To: Dean Amir Mirmiran

College of Engineering and Computing

This thesis, written by Deepika Nirmal, and entitled Environmental and cost impact analysis of materials and assemblies in building construction, is referred to you for judgment.

We have read this thesis and recommend that it be approved.

Irtishad Ahmad

Emre Bayraktar

Wallied Orabi, Major Professor

Date of Defense: March 30, 2012

The thesis of Deepika Nirmal is approved.

Dean Amir Mirmiran College of Engineering and Computing

Dean Lakshmi N. Reddi University Graduate School

Florida International University, 2012 


\section{DEDICATION}

This thesis is dedicated to my father and mother. Without their support, patience, understanding and most importantly love and blessings; the completion of this work would not have been possible. I would also like to thank my siblings for being the best brothers and sister in constantly encouraging and giving me strength to concentrate. 


\section{ACKNOWLEDGMENTS}

I wish to express my sincere gratitude to my major advisor, Dr. Wallied Orabi, for his insightful guidance and constant encouragement. He gave me the opportunity to grow as a professional and as an individual. This accomplishment would not have been possible without my mentor, Dr. Irtishad Ahmad, whose continuous belief in me has

brought me to where I am today. I am also thankful to Dr. Emre Bayraktar for his professional knowledge and helpful recommendations.

My heartiest thanks extend to all my close friends who have always inspired me to be a better person.

Lastly, I offer my regards and thanks to all who supported me in one-way or another in the completion of this project. 


\begin{abstract}
OF THE THESIS
ENVIRONMENTAL AND COST IMPACT ANALYSIS OF MATERIALS AND ASSEMBLIES IN BUILDING CONSTRUCTION
\end{abstract}

by

Deepika Nirmal

Florida International University, 2012

Miami, Florida

\title{
Professor Wallied Orabi, Major Professor
}

One of the new trends in the building construction industry is designing for environmental-friendly buildings, a.k.a. Green Buildings. Planners and designers are therefore trying to accommodate these new environmental practices into existing design criteria. Selection of building materials is one of the key decisions need to be made by building designers. However, due to the strong influence of costs on the building industry, making material-selection decisions solely based on their environmental impacts could be both inadequate and impractical. These factors therefore complicate the building design process, especially pertaining to material selection.

Accordingly, the present study is aimed at providing much needed support to the decision-making process of residential building design. To this end, the study evaluates and analyzes the environmental and cost impacts of several building assemblies and material alternatives for the building exterior walls. The Technique of Order Preference Similar to Ideal Solution (TOPSIS) is used to evaluate and rank different material alternatives used in walls based on their environmental impacts. In addition, the environmental data used in this study were extracted from commonly used databases that considered the lifecycle impacts of different residential building materials and assemblies. The environmental and cost impacts of several exterior wall assemblies are then aggregated for different building material alternatives to allow 
for an objective comparison of these assemblies and facilitate proper building design decisionmaking. The study results show that wood and exterior insulation finishing system (EIFS) provided the best environmental performance of wall structural and wall finishing materials, respectively. This research is expected to prove useful in supporting building design decisionmaking. In addition, this research can improve pre-construction estimation and support screening of building materials. 


\section{TABLE OF CONTENTS}

CHAPTER

PAGE

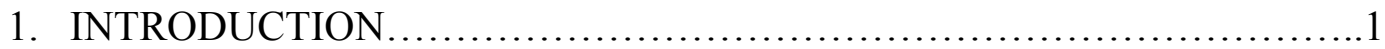

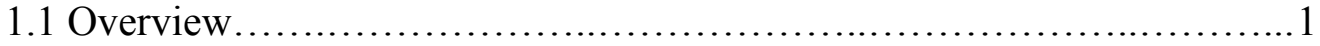

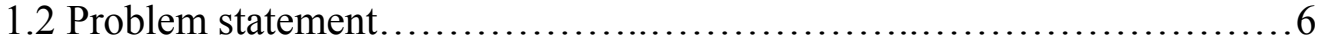

1.3 Research objectives................................................... 8

1.4 Research methodology ............................................. 10

1.5 Thesis organization..................................................

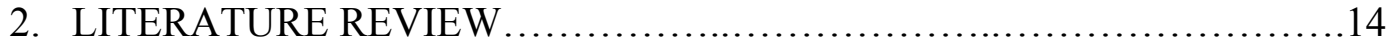

2.1 Introduction......................................................... 14

2.2 Evaluation of environmental impacts of building construction............14

2.3 Analysis of cost impacts of building construction........................ 18

2.4 Selection-models assisting decision-making .......................... 20

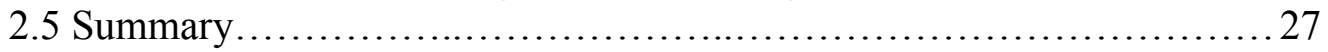

3. IDENTIFICATION OF SIGNIFICANT ALTERNATIVES (MATERIALS

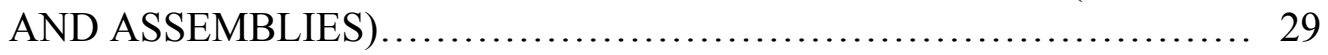

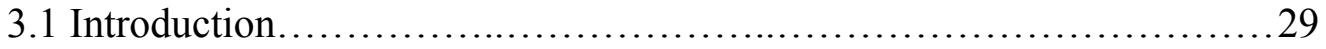

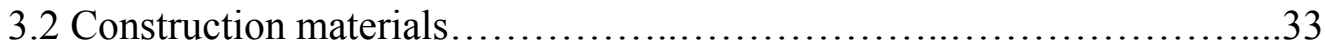

3.3 Building component assemblies.....................................43

3.4 Impact indicators ................................................... 47

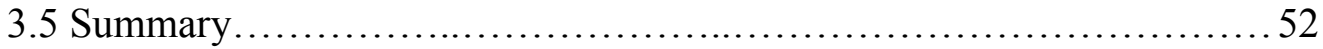

4. OVERALL ENVIRONMENTAL IMPACT ASSESSMENT..................54

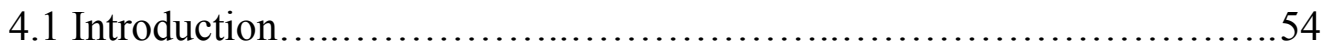

4.2 Assessing environmental impacts of materials.........................57

4.3 Assessing environmental impacts of component assemblies..............62

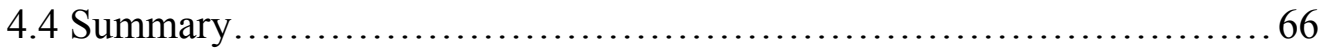

5. EVALUATING ENVIRONMENTAL AND COST IMPACTS................67

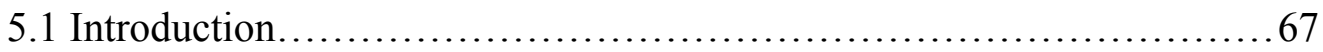

5.2 Analyzing combined impacts of materials and component assemblies....68

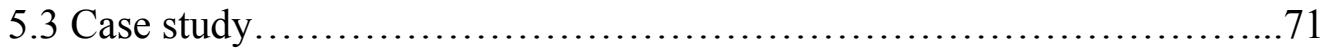

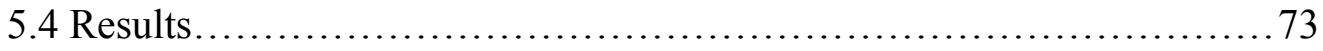

5.5 Evaluation tool........................................................... 74

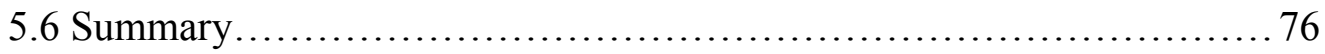

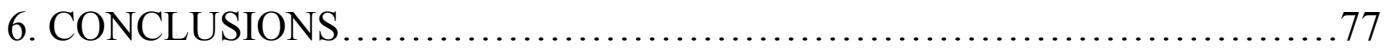

7. RECOMMENDATIONS FOR FUTURE RESEARCH......................78

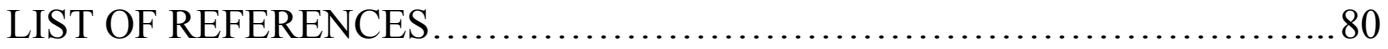




\section{LIST OF TABLES}

TABLE

PAGE

2-1 Overview of LCA tools..................................................... 27

3-1 Classification of elements of building components............................. 33

3-2 Commonly used materials............................................. 34

3-3 Screening wall materials through data availability.............................34

3-4 Screening wall materials through data sources................................. 36

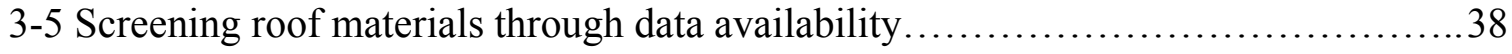

3-6 Screening roof materials through data sources............................... 38

3-7 Screening component assemblies through data availability $\ldots \ldots \ldots \ldots \ldots \ldots \ldots \ldots . \ldots 3$

3-8 Screening component assemblies through data sources........................ 44

3-9 Screening impact indicators through data availability .........................50

3-10 Screening impact indicators through data sources............................51

3-11 Set of materials for exterior walls.........................................

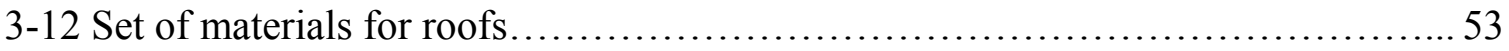

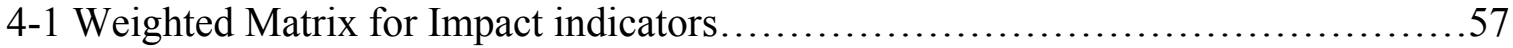

4-2 Performance of alternatives............................................. 57

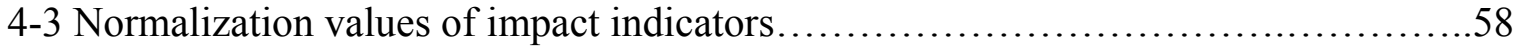

4-4 Normalized Decision matrix ...........................................59

4-5 Weighted Normalized Decision matrix.................................59

4-6 Separation measures..................................................61

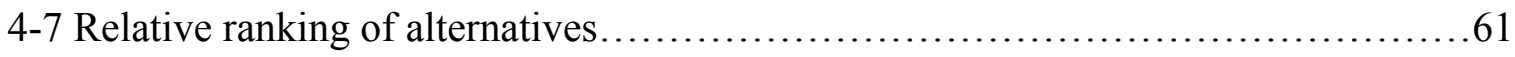

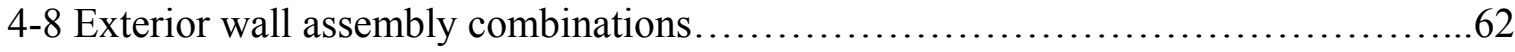


4-9 Impacts of wall assemblies per SFT.

5-1 Types of Decision Support Tools........................................67

$5-2$ Materials and assembly combinations....................................68

5-3 Recalculation of performance of Assemblies..............................69

5-4 Environmental Impacts of Building's exterior wall..........................

5-5 Environmental scores and cost of assemblies................................ 74 


\section{LIST OF FIGURES}

FIGURE

PAGE

1-1 Impacts of Building Construction..........................................

1-2 Statistics of Impacts of buildings....................................... 2

1-3 Traditional and Sustainable Design Criterion...................................

1-4 BEES Framework Analysis................................................ 6

1-5 Research Tasks......................................................10

2-1 Process involved in Building Construction.................................... 15

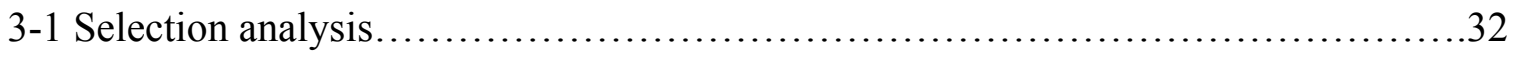

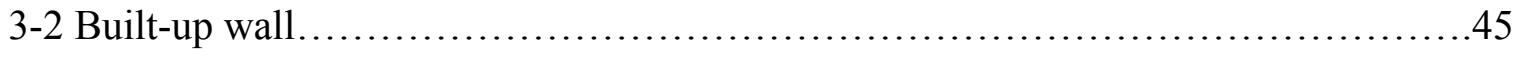

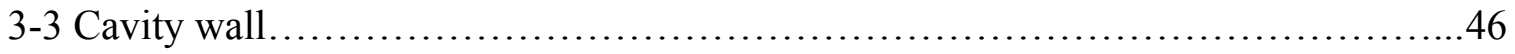

3-4 Built-up roof.....................................................47

4-1 Qualitative evaluations for effective selection..............................56

4-2 Fossil fuel depletion comparison (measured in MJ) .........................6 65

4-3 Global warming potential comparison (measured in $\mathrm{kg}$ of $\mathrm{CO}_{2}$ )...............6 65

4-4 Health quality index comparison (measured in microDALY) $\ldots \ldots \ldots \ldots \ldots \ldots \ldots \ldots . \ldots 6$

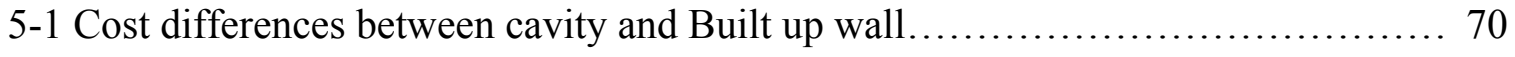

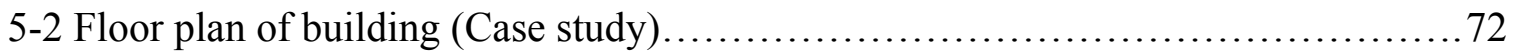

5-3 Cost impacts of Building's exterior wall.................................. 73

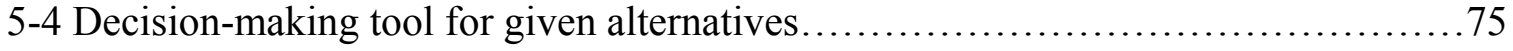




\section{CHAPTER 1: INTRODUCTION}

\subsection{Overview}

The Buildings Energy Data Book, by U.S. Department of Energy, approximates an average life of 75-80 years for buildings in most developing countries. This implies that buildings will have long-term effect on its structural performance and also on the environment. Impacts of buildings and its construction need not be always negative. Structures that are well-planned and built with sustainable materials and methods can be very beneficial to both community and workers as well. However, buildings have more impacts on environment than on other impact categories (Figure 1-1) and the consequences can be both direct and indirect.

\section{Environmental}

- Resources

$\cdot$ Ecosystem

\section{Economic}

-Productivity

-Incurred costs

\section{Social}

- Comfort

-Aesthetics

\section{Cultural}

-Historic value

Figure-1-1: IMPACTS OF BUILDING CONSTRUCTION

The construction industry in U.S. is very robust and with its growing, the environmental burdens are also increasing. This is because building construction sectors 
are major consumers of energy, land and raw materials. According to Horvath, the construction industry is the largest user of materials by weight in the United States (Horvath 2004). For example, buildings consume about $40-50 \%$ of all energy generated (GreenSource Magazine, 2008) and about $40 \%$ of total raw materials consumption by weight (USGBC, 2002). Buildings are also responsible for potentially harmful atmospheric emissions. Approximately 1.6 million people die every year due to air pollution caused by poor air quality (WHO, 2005).

Percentage of U.S. Annual Impact

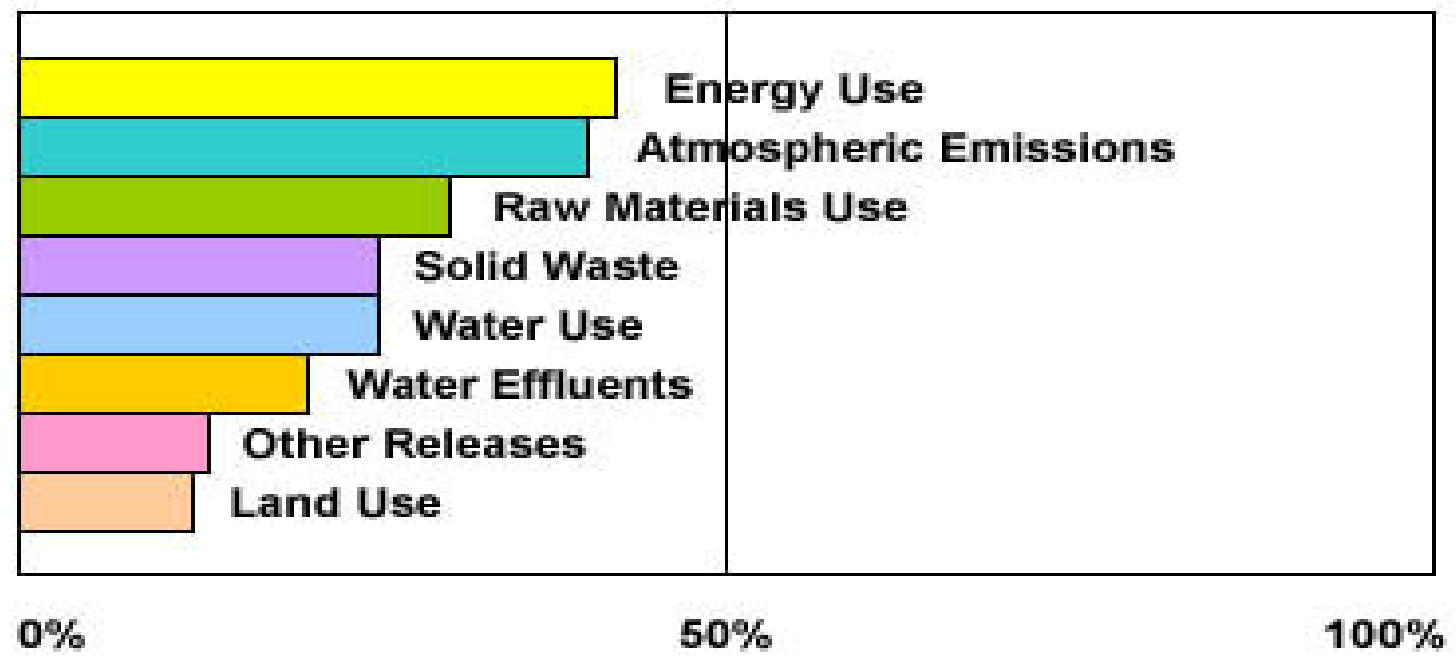

FIGURE 1-2: STATISTICS OF IMPACTS OF BUILDINGS (SOURCE: EPA, 2004)

This increasing problem calls for a resolution that is integrated and agreeable in its approach. A commitment to conserve environment and an aim to balance the ecological, societal and economic benefits can often be associated with commonly known Sustainable Design. Few important principles of sustainable design are:

- Use of Environmentally Preferable Products

- Optimized use of Energy

- Conserving resources 
- Enhancing Indoor Environmental Quality etc (Whole Building Design Guide).

Kibert states that in addition to cost, time and quality objectives, sustainable designs add to it the criteria of minimizing of resource depletion and negative environmental impacts and enhance a healthy living environment (Kibert 1994). This can be precisely illustrated through figure 1-3.

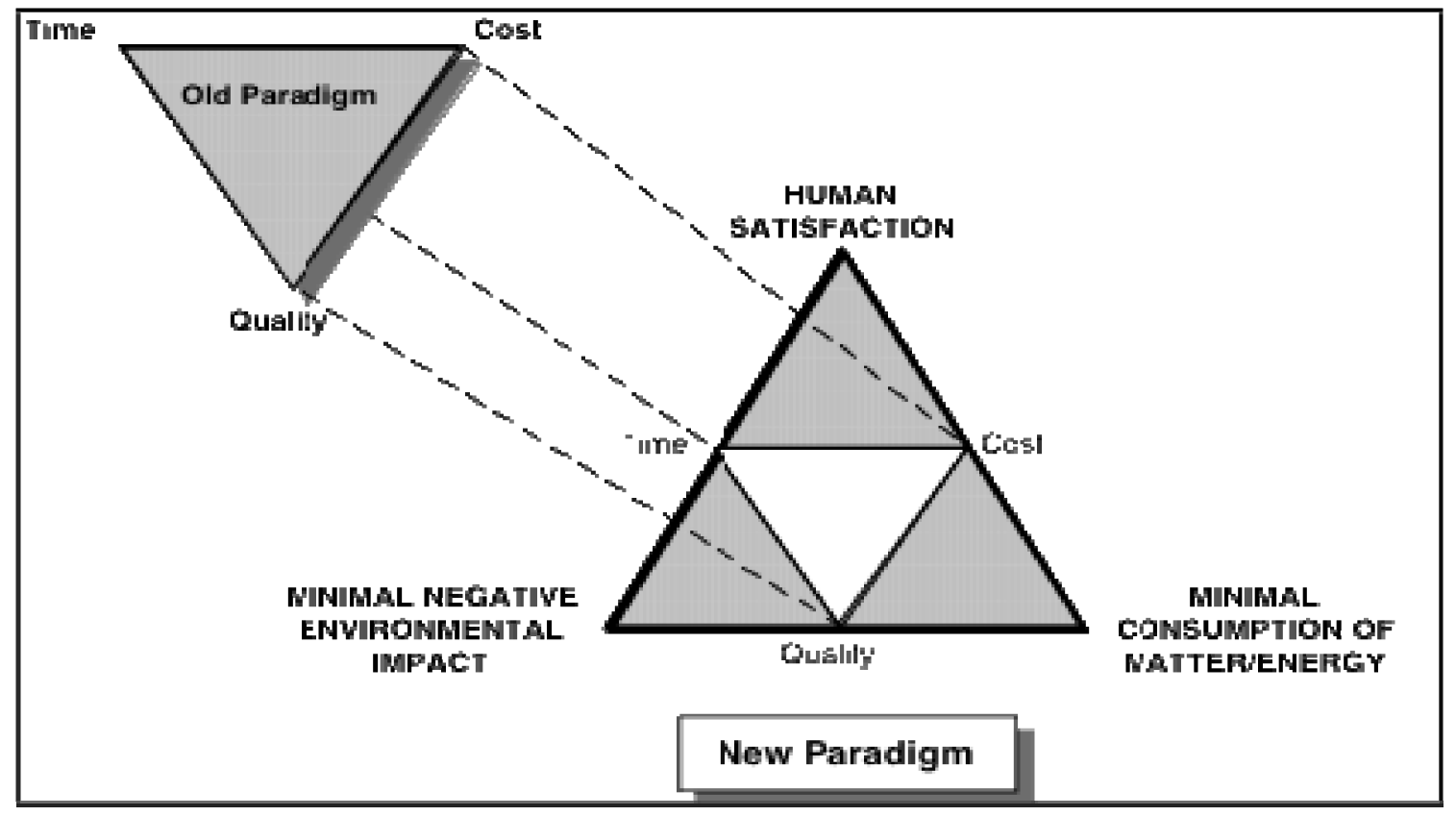

FIGURE 1-3: TRADITIONAL AND SUSTAINABLE DESIGN CRITERION (KILBERT 1994)

Minimizing the environmental hazards can be done in two ways:

(i) Reducing the consumption of construction materials: Recycling or reusing the construction materials will prevent from using the new resources thereby saving the natural resources.

(ii) Selecting the right construction material: A judgmental tool that evaluates the environmental performance of a material can help the designers to accomplish the goal of mitigating negative impacts on the environment. 
Accordingly, in order to obtain these objectives, decision has to be made at every stage of the life cycle of the building facility. Before making decisions about incorporating sustainable designs, the decision-makers will need to assess the long-term and short-term impacts of those decisions on the environment. With the discrete character of the construction industry, the process of construction requires growth and segregation in order to identify their environmental implications. As stated above, the implications include use of resources and energy and emissions to air, water and land. The negative effects of these implications increase as project teams make poor decisions which mostly results by having limited criteria like low investment cost etc.

Most studies indicate that a substantial reduction of environmental impacts can be achieved through more improved choice of materials used for the construction. For example, the LEED, one of the widely used green building assessment tool in the U.S., emphasizes on the use of recycled materials, renewable resources and purchase of locally available materials in order to lessen the negative impacts on the environment (USGBC, 2005).

In addition to the impact caused by different material choices, building component assemblies also effect the environment in various ways. The term "Building Component Assembly" in this research refers to the way a building is built i.e., the method used to construct walls, roofs etc. Different building component assemblies use different amounts of energy in the production or transport and they are also responsible for producing harmful gas emissions. Some component assemblies can be re-used or re-cycled and some are responsible for producing more waste than others. 
Building component assemblies can be combined with use of different construction materials to get the benefits of each. For example, you can have a lightweight wall and a heavy weight wall on different sides of a house, depending upon the degree of insulation required based on the orientation of the building.

The building can face increased risk (for example weather tightness problems, improper insulation, etc) if it is not properly designed and constructed. Therefore, to ensure a successful combination of different building component assemblies and construction materials a competent design advice is required.

There are numerous different tools proposed and available that compare products or materials from an ecologically sustainable aspect. ATHENA EcoCalculator and Building for Environmental and Economic Sustainability (BEES) are the tools worth mentioning. These tools are primarily based on the life-cycle assessment (LCA) methodology that evaluates the environmental impacts of materials over their life cycle. ATHENA's EcoCalculator assesses most of the structural and envelope system assemblies, typically used in both residential and non-residential buildings. Its database mainly contains energy use and air emissions, which are considered as the impact categories (Jincheng, 2001). BEES model typically measures the performance of building products from an environmental perspective by using the life-cycle assessment method that is specified in the ISO 14040 series of standards. Additionally, it also measures the economic performance using the ASTM standard life cycle cost method. An aggregate score is obtained (figure 1-4), that combines both the environmental and economic performances, using the Multi- Attribute Decision Analysis by ASTM standard (Gerfen 2005). 


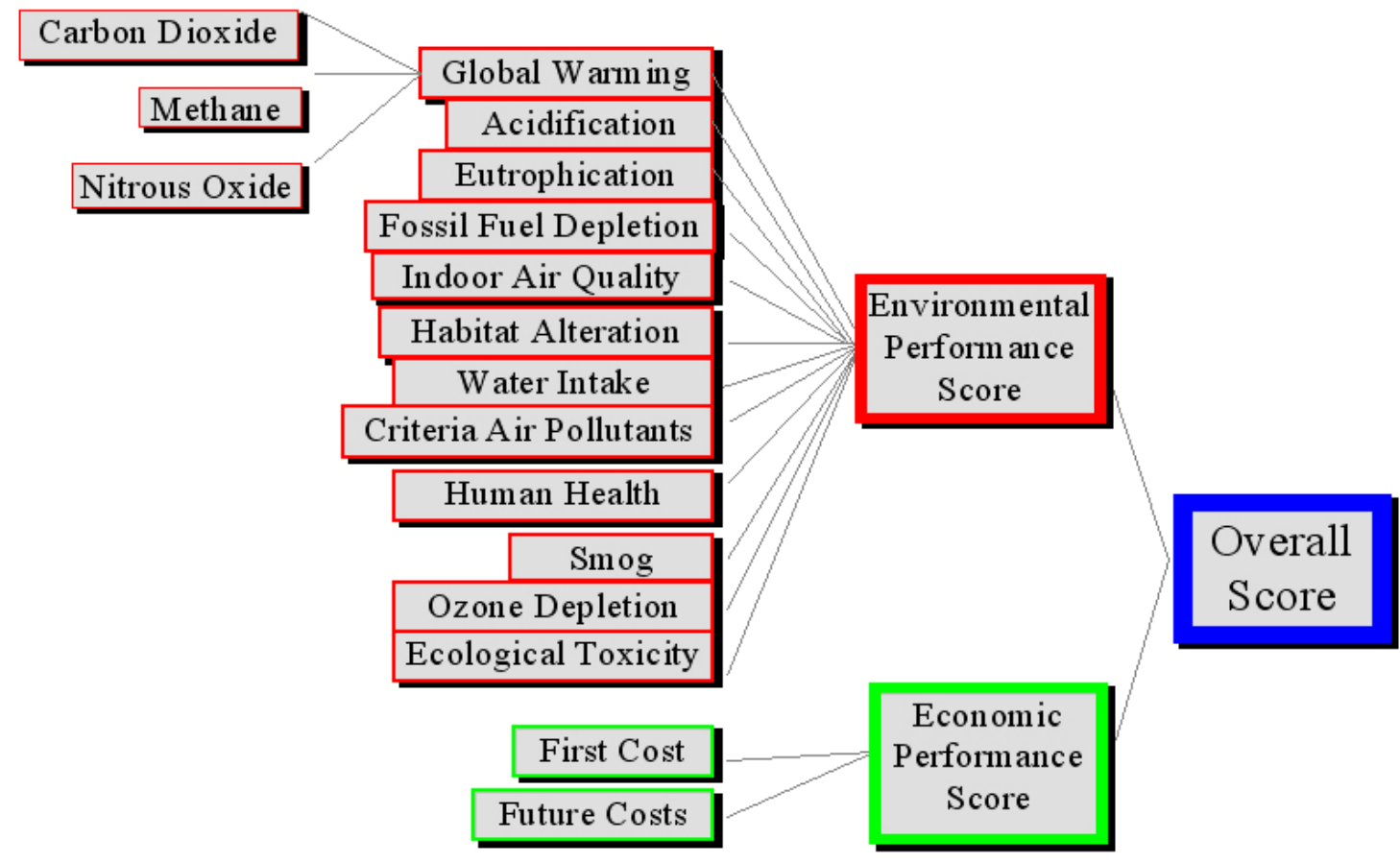

\section{FIGURE 1-4: BEES FRAMEWORK ANALYSIS (SOURCE: BEES 4.0)}

In spite of the results achieved by the aforementioned software, in modeling a design-aid tool for sustainable material selection, there is still an abridgement required for a flexible procedure, which enables the designer to choose the sustainable construction materials and component assemblies.

Hence, in an effort to bridge this gap and to assist designers or decision-makers with effective decision-making, there is a pressing need for a selection-tool that is capable of analyzing the impacts of different combinations of construction materials and component assemblies from cost and environmental perspective.

\subsection{Problem Statement}

To enable the development of the above-mentioned selection tool useful for assisting decision makers, the present study will completely investigate on three of the main problems: (1) identifying the most significant construction materials, component 
assemblies and impact categories, (2) aggregating the environmental impacts categories together for the chosen materials (3) comparing the impacts of different combinations of materials and component assemblies.

Firstly, with many choices of building materials and component assemblies available, it becomes quite a concern about choosing the best ones for your project. An answer for this lies in setting up criteria for your selection like suitability to your design in terms of cost or aesthetics etc. It is therefore essential for decision makers to be able to identify the most significant construction materials and component assemblies from an environmental and cost perspective. In addition to the construction materials and component assemblies, there are also numerous types of impact categories that effect environmentally and economically at various stages of the life cycle of a building. Hence, there is a need for a common measuring platform that is capable of identifying the material based on its aggregate impact.

Secondly, in order to select a material alternative based on its environmental impacts, it is to be noted that the kind of impact it has also makes a significant difference. For example, material A can generate high greenhouse gas emissions and produce less wastes over its life cycle when compared to material B, which produces less greenhouse gases but generate more wastes. This implies, that assessing an alternative solely based on individual impact categories might not give an effective solution to decision-making. To balance the trade-off between various impact categories the solution lies in assessing the materials based on its overall environmental impact. Hence, there is also a need to identify the impact categories that has the highest negative impact environmentally and cost-wise, which will enable in efficient decision-making. 
Thirdly, along with the impact each material has, the kind of impact created while constructing a building component also plays a significant role. In addition to the environmental impacts, cost is also the prime factor considered when calculating the impact of the selected building material and component assembly. It is believed that cost is typically inversely proportional to the impact on the environment. For example, a less costly exterior window assembly may not be as energy efficient as more expensive one. Each of these conflicting objectives has a significant impact on the decision-making process. Accordingly, there is a need for comparing alternatives based on the aggregate environmental impacts and costs and considering the trade-off between maximizing environmental benefits and minimizing costs at all stages of its cycle.

Finally, to address the gap in the previous researches about comparing the impacts of various building materials and component assemblies individually, there is a pressing need for a comparison- tool that is capable of comparing the environmental and cost impacts of combinations of construction materials and component assembly.

\subsection{Research Objectives}

The main goal of this study is to develop an evaluation tool that would assist the decision makers in choosing the right construction material and component assemblies from an environmental and cost perspective. In an effort to accomplish this goal, this study typically identifies the following objectives along with related research questions and hypotheses:

\section{Objective 1:}

To identify significant materials and assemblies associated with various environmental impact categories. 


\section{Research Questions:}

(a) Which components of a building are responsible for significant impacts on the environment and economy?

(b) What are the most common materials and component assemblies that are used building construction?

(c) Which impact categories contribute the most in creating negative impacts on the environment?

\section{Hypothesis:}

Identifying the significant materials, component assemblies and environmental impact categories can support in selecting and working towards environmental and cost sustainability, out of numerous available alternatives.

Objective 2:

To evaluate and compare the overall environmental impacts of materials.

$\underline{\text { Research Questions: }}$

(a) What is the significance of each impact category towards environmental performance?

(b) How can the impact categories be compared against other impact categories (relative significance)?

(c) How can different impact categories be aggregated to a single measuring unit?

\section{Hypothesis:}

The aggregated score of various impacts categories together can support in analysis of alternative construction materials and component assemblies from an environmental perspective. 


\section{Objective 3:}

To analyze the environmental and cost impacts of materials and assembly combinations.

\section{$\underline{\text { Research Questions: }}$}

(a) How is the compatibility between different construction materials and component assemblies defined?

(b) How can the impacts of both construction materials and component assemblies be measured and quantified?

(c) On what basis is the optimal result of the analysis compared?

Hypothesis:

Efficient evaluation models can provide the capabilities of identifying and analyzing optimal combination of construction material and component assembly that can help the decision makers in making and effective selection.

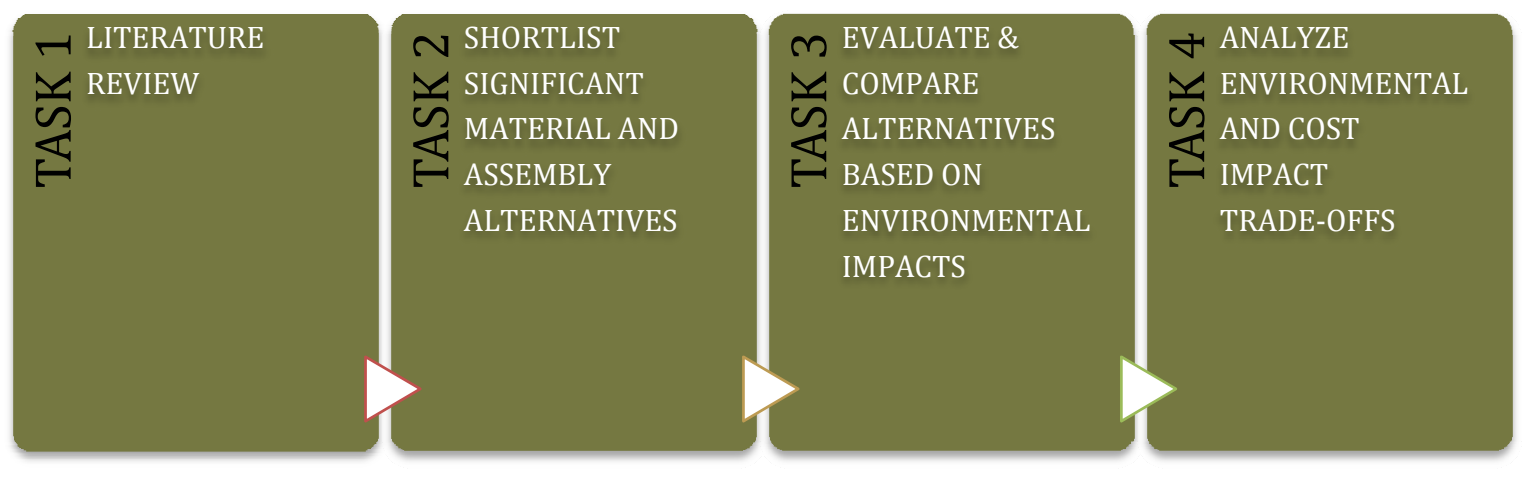

Figure 1-5: Research Tasks

\subsection{Research Methodology}

To accomplish the aforementioned objectives, the present research study is organized into four main research tasks: (i) Conduct an extensive literature review on previous studies focusing on different impacts caused by buildings and its construction, 
(ii) Identify the set of alternatives required for construction of building elements, (iii) Analyze and obtain the cumulative impact of various categories and (iv) formulate a tool to evaluate the cumulative impact of combinations of construction materials and component assemblies. Each task in this research supports towards a progression of the subsequent task.

\subsubsection{Task 1: Conducting an extensive Literature Review}

This task is focused to examine the previous researches done on the materials and design involved in building construction. The main objective of this task is to identify the research gaps in the previous similar researches and address in this study. This objective is further divided into 3 sub-tasks:

1- Survey few existing selection-models and examine their potential in assisting designer/ architects in making a decision for the design

2- Review research studies focusing on evaluating the environmental impacts of building construction

3- Investigate previous studies focusing on analyzing the cost impacts of building construction

1.4.2 Task 2: Identifying significant materials, assemblies associated with various environmental impact categories.

The main objective of this task is to shortlist construction materials, component assemblies and impact categories from a set of alternatives. In an attempt to obtain above-mentioned set of determinants, this present task is subdivided into the following sub tasks: 
1- Determine the building components that are importantly responsible for environmental and cost impacts

2- Define a strategy to enlist the most common materials and component assemblies

3- Analyze the significant impact categories from an environmental perspective

\subsubsection{Task 3: Evaluating and comparing the environmental impacts of material} $\underline{\text { alternatives }}$

The present task in this study mainly aims at obtaining a score that aggregates the environmental impacts which further supports in the analysis of the overall impact a material or component assembly has. To do this, a multi criteria decision-making method; TOPSIS is used and is further divided into the following sub-tasks:

1- Identify the role of each impact category towards environmental performance.

2- Formulate a matrix that will define the performance of each alternative against each impact category.

3- Compare and rank each alternative based on ideal solution.

1.4.4 Task 4: Analyzing the environmental and cost impacts of materials and assemblies combination.

The main objective of this task is to analyze the combined impacts that would assist decision makers in selecting the right combination of construction materials and component assemblies that can have a low negative impact on environment and cost perspective. In order to do this, the following sub-tasks are created:

1- Evaluate the aggregate environmental impacts of different possible assemblies

2- Calculate the incurred costs of each combination of material and assembly 
3- Analyze the trade- offs between environmental and cost impacts.

\subsection{Thesis Organization}

The present research is organized into following Chapters in order to relate each one of them to the main study.

Chapter 2 presents an extensive literature review on all relevant research studies that aimed at addressing ecological sustainability issues. The previous works examined include studies on evaluating the environmental \& cost impacts of building construction and existing tools available for selecting construction materials and component assemblies.

Chapter 3 aims at identifying relevant construction materials and component assemblies by analyzing all available set of alternatives and short-listing the most significant ones. In addition to these, the associated impact categories are also identified.

Chapter 4 discusses the methods of aggregating different impacts that are identified in the previous section. The different impacts constitute towards various environmental categories.

Chapter 5 aims at constructing an evaluation tool that analyzes combined impacts of construction materials and component assemblies. This will enable the decision makers in effectively selecting the alternatives best suitable to their project considering environmental sustainability and costs.

Chapters 6 and 7 summarize and conclude the research progression and also state the contributions of this study. In addition to this, the chapter also recommends the path for further research giving an insight of the gaps in the present research. 


\section{CHAPTER 2: LITERATURE REVIEW}

\subsection{Introduction}

The main division of any research or study is the observational facts of the previous studies conducted within the same domain of the research. Hence, one fulllength chapter of this thesis is dedicated to the review of such studies. An extensive literature review is done on the materials and design involved in building construction. The main aim of this review is to recognize the research gaps and address them in the present study. For a clear understanding, this task is based on the following classification: (1) reviewing research studies that focused on evaluating the environmental impacts of building construction, (2) review previous studies focusing on analyzing the cost impacts of building construction, (3) Survey few existing selection-models and examine their potential in assisting designers/ architects in making a decision for the design.

\subsection{Evaluation of environmental impacts of building construction}

Several research studies focused on analyzing different factors for impacts of buildings on the environment [e.g., energy consumption, greenhouse gas emissions, waste generation, etc. Of all these impacts studied, Global warming potential is the most researched environmental impact [Buchanan, 1994]. This is due to the fact that the greenhouse gases associated with the global warming can be easily quantified than the other impact factors. The most effective results can be obtained by adopting the LCA methodology, as a means of evaluating the environmental impacts of buildings [Sonnemann, 2003]. The previous studies primarily attempted to analyze the environmental impacts focusing on (1) the materials used in building construction (2) the whole building itself and (3) the various stages of life cycle of the buildings. 


\subsubsection{Impacts of building materials involved in construction}

Building materials before having used in the construction, are found in the natural impure form (e.g., from ores as raw materials). Using the final product of these raw materials involves an energy consuming process and in addition also produces waste [Asif, 2007]. This extraction process is done in steps and these steps can be grouped into phases involved in the product's life cycle [Figure 2-1]. At each stage, there are associated impacts on the environment. In order to quantify these environmental impacts, there have been many studies performed, most of which incorporated the LCA methodology.
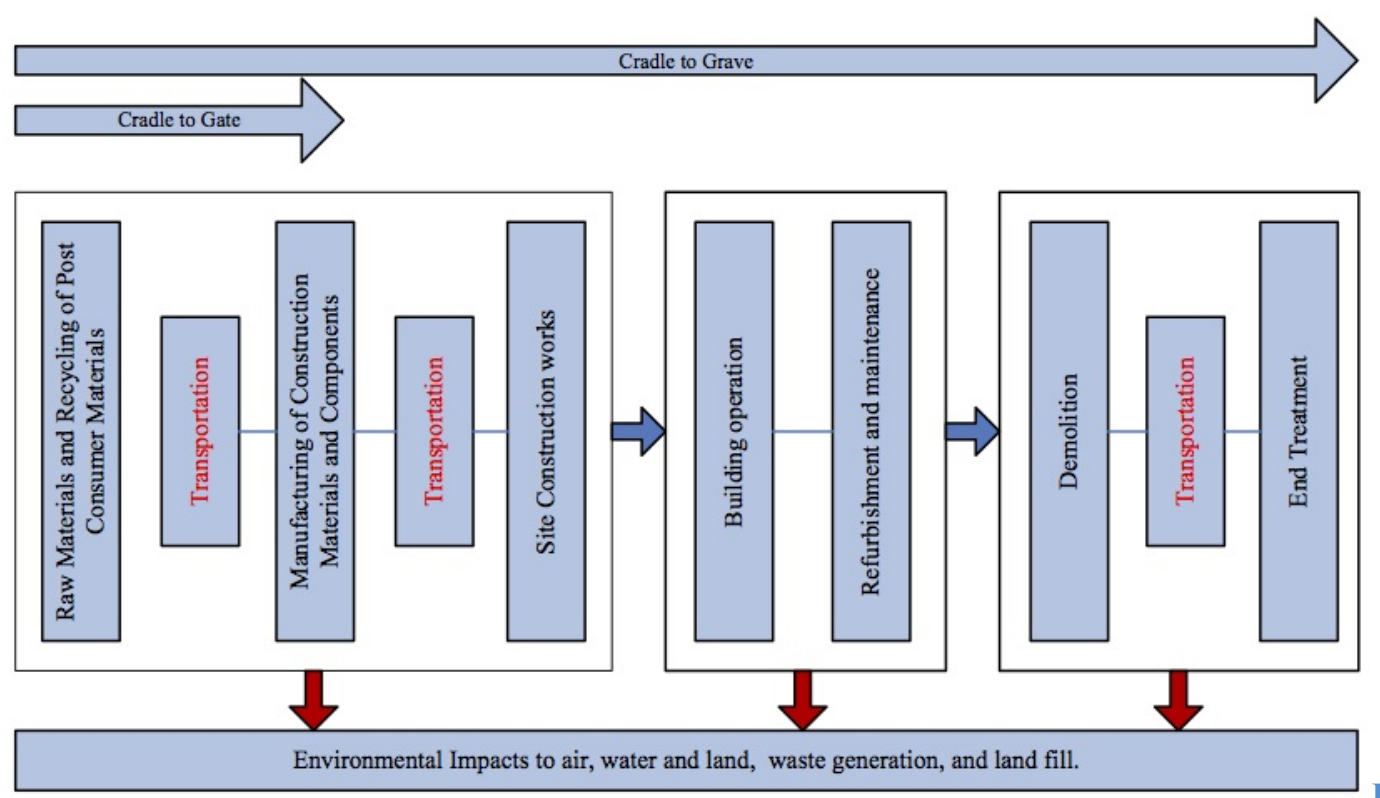

Figure

2-1: Process involved in a Building Construction

Morel conducted a research on analyzing how materials used in a building construction can reduce the environmental impact, if they are resourced locally than importing it from a distant site. This concept was validated by comparing the energy consumption of two houses; (a) built with locally resourced materials and (b) a typical concrete house. The analysis concluded that the amount of energy and the impact of 
transportation used in building type- a, is decreased by a significant ratio than building type- b [Morel et. al., 2000]. Extensive study is conducted by many researchers on comparing wood with other alternative building materials focusing on the impacts on environment. Petersen and Solberg analyzed the impacts concentrating mostly on the greenhouse gas emissions, economics and methodological issues. The study, after a complete review on comparing wood with other building materials like steel, concrete, vinyl, etc., concluded that wood stands as the best alternative in terms of low GHG emissions, less $\mathrm{SO}_{2}$ emissions and less waste generation [Petersen, 2003].

Apart from focusing on locally resourced/ available materials, there have been studies that compared different construction materials, irrespective of local/ non-local resources. One such research was conducted by Asif and Muneer, in which they compared embodied energy of 8 various materials in a Scottish dwelling. The research concluded by stating that among the 8 materials examined, concrete alone consumed about $65 \%$ of the total embodied energy of the 3 -bedroom house and in addition to this it was responsible for significant environmental impacts [Asif, 2005]. One particular research study by Nicoletti compared two materials, applicable to only a single component of a building. A comparative LCA between two flooring materials was carried out and the one with better environmental profile was identified. Out of these two materials; marble and ceramic tiles, the ceramic tiles was found to have a significant role in relevant harmful gas emissions, whereas the energy consumption was almost equal in both the types of materials [Nicoletti, 2002]. 


\subsubsection{Impacts of Building as a whole}

It is a well-known fact that the greatest contributors to green house gas emissions are the buildings, which account for approximately $50 \%$ of global carbon dioxide emissions [Raynsford, 1999]. Buildings consume about $40 \%$ of the materials and generate huge amounts of harmful gas emissions [California Integrated Waste Management Board, 2000]. In addition to the emissions of harmful gases, the building's operation stage can have a significant impact on the environment during its whole life cycle [Citherlet, 2001].

There have been many measures introduced with an aim to reduce the negative impacts from a building sector [Bowie, 2002]. Before suggesting any measures, there is a need to first analyze the negative impacts associated. Accordingly, there has been extensive research done on evaluating the impacts of buildings in many ways.

A study of 3 single-unit dwellings, by Adalberth showed the difference between quantity of materials and quantity of energy consumption. As per the analysis, the concrete used was $75 \%$ by weight but the energy consumption was only $28 \%$ [Adalberth, 1997]. After analyzing, that the embodied energy accounted for $45 \%$ of total energy requirement, Thormark concluded that by using low-energy dwellings, the energy consumption would be recovered by about 37\%- 42\% [Thormark, 2002]. Junnila et. al. compared two buildings throughout their life cycle, involving about 42 different building materials. One building was located in Europe and the other in United States. After thorough comparison it was found that the emissions ratio of different life cycle phases to the total emissions was almost same for the two buildings [Junnila, 2006]. Xing et. al. conducted another study which compared the two different structured office building. 
The energy consumption associated with the building materials was analyzed and was found that consumption from steel-framed building was $24.9 \%$ that of concrete-framed building. The energy consumption associated with the whole building with steel structure was calculated as $75.1 \%$ that of the concrete framed structure [Xing, 2008].

\subsubsection{Research studies focused on different phases of the Building construction}

In addition to all the aforementioned research studies discussed, that are classified according to the subject of analyses, like building materials or buildings as a whole, few research studies have also focused on the stages of life cycle of the buildings and/or building materials.

Adalberth in the same research as mentioned in section 2.2.2, also focused on studying the energy use during the life cycle of three single-unit dwellings. In this study it was concluded, after performing analysis, that the use-phase has the major environmental impact, say about 70\%- 90\% [Adalberth, 1997]. Likewise, in the same study by Junnila and colleagues as mentioned in the previous section, it was analyzed that the use-phase of the building had the maximum environmental impact [Junnila, 2006]. In a study, previous than the aforementioned research, the same author stated that in an office building, almost all of the life-cycle phases could have a substantial impact on the environment, but the majority of the impact categories, about $45 \%$ in significance, were not considered. Hence, the operational and manufacturing phases would have had the significant impact if all of the important impact categories were studied (e.g., ozone depletion, biodiversity loss due to lack of data, etc) [Junnila and Horvath, 2003]. 


\subsection{Analysis of cost impacts of building construction}

Any building material, in addition to the environmental impacts, also has a significant impact on the costs. This could include the cost of the material, the cost of the construction, the health costs and the productivity gains/losses associated with its use. For example, according to Fisk, there could be a substantial annual health cost saving by experiencing better indoor environments. To approximate in figures, an estimate of \$6$\$ 14$ billion from reduced respiratory disease, $\$ 1-\$ 4$ billion from reduced allergies and asthma, \$10- \$ 30 billion from reduced sick building syndrome symptoms can be saved annually respective to the health costs.

As a part of the Life cycle assessment, the Life cycle costing is an additional evaluating technique that concentrates on analyzing the cost impacts of building construction. The life cycle costs usually is made up of the following items [Davis 2007]:

- Cost of controlling atmospheric emissions

- Cost of resources (water and energy consumption) [used for extraction and production procedures]

- Cost of waste disposal

- Cost of waste treatment including solid and other wastes

- Cost of eco-taxes

- Cost of pollution rehabilitation measures

- Cost of environmental management

- Investment costs, service costs, maintenance costs, and refurbishment Costs.

The use of this life cycle costing methodology first started with the US defense industry [LaGrega, 1994]. The main aim of originating such methodology was to 
consider the operational and maintenance costs of systems. After this concept of Life cycle costing was introduced, many attempts were made in incorporating this methodology to the various industrial sectors including the construction industry.

\subsection{Selection models assisting in decision-making}

Decision-making has always been tough and it takes lots of effort and compromises to conclude to a particular decision. This is applicable to any case, also to our day-to-day living. When it comes to huge initial investments/ costs, decision-makers face criticality in tackling them. Decision-making criteria can be one or more, where more than two it is called multi-criteria decision-making. The multi-criteria decisionmaking takes into account the percentage of significance of each criterion and reaches an acceptable/ satisfactory solution. There are many decision-making techniques that help the decision-makers in providing solution to the problems. With the growing awareness of the environmental issues, there is a need to incorporate environmental, social and cost considerations. This resulted in the advanced utilization of the multi-criteria approaches. Various methods of decision-making are available; priority based, out-ranking based, distance based and mixed methods. One effective methodology is the Life-cycle Assessment (LCA) that evaluates the sustainability of products by identifying and quantifying energy and materials used and wastes released over its entire life cycle (Trusty 2003).

In building construction, an LCA is generally conducted over the full building life cycle, including materials manufacturing, construction, operation, and decommissioning. LCA is generally accepted as a functional tool that quantifies environmental impacts and performance of systems (Trusty 2003, Mora 2005, Ljungberg 2007, Abeysundara et al 
2009, Bayer et al. 2010, and Florez 2010). Although LCA is relatively new to the building sector, it has been used extensively since its conception in the 1960s.

The International Organization for Standardization (ISO) 14040 series describes four general steps to be performed in any LCA: goal and scope definition, inventory analysis, impact assessment and interpretation. The goal and scope definition phase defines the process or product to be assessed, and identifies the level of detail of the analysis to be performed, and the impact categories to be evaluated (Bayer et al. 2010, BDC 2005). The inventory analysis step quantifies and categorizes the inputs and outputs of a system, that is, energy and materials used and the emissions to air, water, and land. This phase is also known as the life-cycle inventory (LCI) phase (Bayer et al. 2010, BDC 2005). The impact assessment portion of the LCA process translates LCI information into specific environmental indicators or impact categories, such as global warming, eutrophication, and smog formation. Impact assessments differ from one LCA tool to another since it is based on the judgment and value of impacts. The final phase of LCA is the interpretation of results, where benefits and limitations are outlined in order to make effective environmentally friendly decisions (Bayer et al. 2010).

An overview of commonly used LCA resources is provided as follows:

\section{U.S. Life-Cycle Inventory (LCI) Database}

In order for tools to provide results, information needs to be entered, and for LCA tools, the inputs are in the form of life-cycle inventories (LCI). The publicly available, U.S. Life-Cycle Inventory (LCI) Database, was developed by the National Renewable Energy Laboratory (NREL) and the ATHENA Institute as a resource to create extensive LCI's and LCAs (NREL 2004). The goal of the U.S. LCI database is to provide a central 
source of transparent and consistent information for the U.S. region (Bayer et al. 2010). Downloadable detailed spreadsheets provide calculated data from commonly used materials, products and processes (NREL 2004).

\section{Tool for the Reduction and Assessment of Chemicals and other environmental Impacts (TRACI)}

The EPA's TRACI is the typical method by which most U.S. LCA tools assess the LCI data. It is an impact assessment tool that provides a consistent set of metrics in the form of impact categories including acidification, eco-toxicity, eutrophication, fossil fuel depletion, global warming, human health cancer, human health criteria, human health non-cancer, ozone depletion, global warming, land and water use, and smog formation (Bare 2010). TRACI quantifies the each potential contribution of a product's inventory flow data into one of the impact categories. Several of TRACI's impact categories were developed specifically for the U.S. using input parameters consistent with U.S. locations (Bare 2010). Other impact categories focus on regional and global impacts such as smog and global warming, respectively. All impact categories were selected based on their consistency with EPA research and other developing literature in the area (Bare 2010).

\section{Environmental Product Declaration (EDP®)}

Purchasing "green washed" products can be avoided by selecting products that are certified based on their LCA evaluation approach. The standards of ISO 14020 series, specifically 14025 "Type III environmental declaration certified products", evaluate products using systems that represent the closest alignment to LCA metrics (BDC 2005). Programs like the Environmental Product Declaration ${ }^{\circledR}($ EDP) are increasing the market 
value of products by providing quantitative and verified information about the environmental performance of products based on international standards for LCA such as ISO 14025 and 14040 (EPD 2011, Bayer et al 2010). The information is provided by suppliers and verified by third parties (BDC 2005). In addition, the certification of EDP's

must declare data collection and assessment methods, including value choices and subjectivity, the selected LCI analysis and LCIA impact categories, the quality of information in terms of relevance, accuracy and uncertainty, and the insurance of capability and comparability of product information (BDC 2005). This scientifically accepted program is one alternative to using LCA software tools to assess the environmental performance of products.

\section{Life-Cycle Assessment (LCA) Tools}

Performing full LCA studies for each individual product, material, or process from scratch is neither realistic nor cost effective for building professionals. Building professionals interested in the environmental impacts of their projects do, however, have software tools developed by LCA experts at their disposal to facilitate the process. Such tools have product and process databases embedded in them, allowing decision-makers to quickly compare the environmental impacts of systems. This information can guide a simpler product procurement process. LCA tools are defined as environmental modeling software that develop LCI and perhaps provides life-cycle impact assessment (LCIA) information through standards provided by ISO 14000 series of environmental management standards and other LCA procedures (Trusty et al. 1998). The LCA tool uses information from the LCI data database available and converts materials of a product system into quantities of inputs and outputs in the form of resource and energy 
use (inputs) and emissions to air, water, and land (outputs). LCA tools can be classified based on the type of analysis they perform, such as product, assembly, or whole building analysis (Trusty 2003, Bayer et al. 2010). Tools are also classified as region-specific, are considered based on the life-cycle phases they cover, and on the required skill necessary to operate the tool (Bayer et al. 2010). Many tools have an established LCI database, while others can adapt to information from various LCI database sources.

\section{The ATHENA® Impact Estimator}

The ATHENA® Impact Estimator, developed by the ATHENA® Institute, is capable of producing a whole building analysis, based on cradle-to-grave ATHENA® database and U.S. LCI Database (ATHENA Institute 2011). This LCA tool offers an LCIA method, provided by EPA's TRACI that analyzes over 1,200 building material and assembly combinations (Bayer et al. 2010). This tool is widely used due to the regionspecific databases it uses, the ability to allow the user to custom design assemblies from available products and the detailed results it provides (Bayer et al. 2010). Major drawbacks to this tool are the cost and required skills to use it, the limited options of designing high-performance assemblies, and the overall incomplete assessment of whole buildings environmental impacts (Bayer et al. 2010).

\section{The ATHENA® EcoCalculator}

The ATHENA ${ }^{\circledR}$ EcoCalculator was also developed by the ATHENA ${ }^{\circledR}$ Institute as a free LCA tool that assesses more than 400 building material and assembly combinations in the U.S and Canada (ATHENA Institute 2011). It analyzes cradle-tograve information from the U.S. LCI Database and Athena's own datasets using the EPA's TRACI LCI method (Bayer et al 2010). The tool is free of cost and requires no 
particular skill to use it. A limitation of the tool is that it only allows the evaluation of assembly options given that also come with fixed dimensions (Bayer et al. 2010).

\section{BEES® 4.0}

The Building for Environmental and Economic Sustainability (BEES®) 4.0, the latest version developed by the National Institute Standards and Technology (NIST), provides a cradle-to-grave product-to-product comparison of over 230 building products based on manufacturer and supply company information and U.S. LCI database information (Lippiatt 2007). The assessment method adopted by BEES® is the EPA's TRACI, which is used to form the impact categories, with the exception of Indoor Air Quality. This tool is used in the impact assessment step in the LCA process along with the Environmental Problems approach, where product inventory flows are classified and characterized into quantifiable environmental impact categories. The impact categories in BEES ${ }^{\circledR}$ include global warming, acidification, eutrophication, fossil fuel depletion, indoor air quality, habitat alteration, water intake, criteria air pollutants, ecological toxicity, human health cancer and non-cancer, and ozone depletion potential. The impact categories were selected based on their consistency with EPA regulations and policies, the level of commonality with the current literature and state of development and their perceived societal value (Bare 2002). The impact categories are further weighed, normalized, and merged into a final environmental performance score using multiattribute decision analysis (MADA). The BEES system follows the ASTM standard practice for conducting MADA evaluations of investments related to buildings and building systems (Lippiatt 1999, 2007). MADA generates a single measure of desirability for project alternatives by combining qualitative and quantitative data, that is, apples and 
oranges. The system is not capable of providing data for a full LCA of a complete building, as it only produces data for a limited amount of building products (Lippiatt 2007, Bayer et al. 2010). From those products, BEES® only considers materials in product systems that are significant in weight, energy, or cost (Lippiatt 2007, Bayer et al. 2010). At its current stage, BEES ${ }^{\circledR}$ quantifies data representative of U.S averages, which limits the accuracy of building product information in terms of local or regional impacts. Furthermore, EPA's TRACI categorizes a minimal set of impact categories and does not currently include impacts that are considered minimal, or those that are local such as odor, noise, radiation, heat waste, and accidents (Bare, 2002). This method does not place clear environmental importance on the impacts, which negatively alters the subsequent weighing process (Lippiatt, 2007).

\section{The Economic Input Output LCA (EIO-LCA)}

The Economic Input Output LCA, or (EIO-LCA) was developed by the Green Institute at Carnegie Mellon University and estimates the materials and energy resources required for, and the emissions resulting from, products, materials, services, or industries from material extraction phase, to manufacturing, and transportation phase (CMU 2011). Unlike the ATHENA ${ }^{\circledR}$ or BEES ${ }^{\circledR}$ tools which are building assembly and product LCA tools, the EIO-LCA is an embodied energy tool (Bayer et al. 2010). It does not feed from a database or assess inventory information, but only provides estimates on environmental impacts. EIO-LCA systems can aggregate information from several industry types for

one sector, which misinterprets actual information (CMU 2011). The following table summarizes the aforementioned LCA tools. 
Table 2-1: LCA Tools overview

\begin{tabular}{|c|c|c|c|}
\hline LCA TOOL & TYPE OF TOOL & NUMBER OF DATA & LIMITATIONS \\
\hline \multirow[t]{2}{*}{$\begin{array}{l}\text { Athena } \\
\text { Impact } \\
\text { Estimator }\end{array}$} & $\begin{array}{l}\text { Whole building } \\
\text { analysis tool }\end{array}$ & \multirow{2}{*}{$\begin{array}{l}1,200 \text { Building } \\
\text { material and } \\
\text { assembly } \\
\text { combinations }\end{array}$} & User skill required \\
\hline & $\begin{array}{l}\text { Building } \\
\text { assembly } \\
\text { analysis tool }\end{array}$ & & Access on cost \\
\hline \multirow[t]{2}{*}{$\begin{array}{l}\text { Athena Eco } \\
\text { Calculator }\end{array}$} & \multirow[t]{2}{*}{$\begin{array}{l}\text { Building } \\
\text { assembly } \\
\text { analysis tool }\end{array}$} & \multirow{2}{*}{$\begin{array}{l}400 \text { Building } \\
\text { materials and } \\
\text { assembly } \\
\text { combinations }\end{array}$} & Limited assembly options \\
\hline & & & Fixed assembly dimensions \\
\hline \multirow[t]{2}{*}{ BEES 4.0} & $\begin{array}{l}\text { Building } \\
\text { product LCA } \\
\text { tool }\end{array}$ & \multirow[t]{2}{*}{$\begin{array}{l}200 \text { Building } \\
\text { products }\end{array}$} & Limited product options \\
\hline & $\begin{array}{l}\text { Building } \\
\text { product LCC } \\
\text { tool }\end{array}$ & & No assembly options \\
\hline EIO- LCA & $\begin{array}{l}\text { Embodied } \\
\text { energy tool }\end{array}$ & - & Aggregation of information \\
\hline
\end{tabular}

\subsection{Summary}

Based on the above discussions, LCA is highly advocated because it is transparent and multi-dimensional in demonstrating the tradeoffs required to properly select material, components, systems, and assemblies of a project (BDC 2005). At its current stage of development, however, there are not enough economic incentives for the building community to accept it as a selection support system, as it generally consumes more time and resources than it saves for building projects. Furthermore, databases can be 
inaccurate, incomplete or too generalized, requiring the decision-maker to use multiple sources while drawing more assumptions to the analysis. Finally, the lack of benchmarks limits data available, resulting in unnecessary repetition of complex work. It should be noted that these limitations are only temporary, and will be resolved as more research and development is conducted (Bayer et al. 2010).

In addition, many LCA experts argue about the impact assessment methods and the practice of weighing them. Since the methods used to translate and quantify inventories into impacts vary by the complexity of the impact category, information can be interpreted with inconsistency. The results from the impact assessment are further reduced into a single score, adding more assumptions and generalizations to an already existing inconsistency (Bayer et al. 2010). 


\section{CHAPTER 3: IDENTIFICATION OF SIGNIFICANT ALTERNATIVES \\ (MATERIALS AND ASSEMBLIES)}

\subsection{Introduction}

This chapter mainly aims at addressing the issue in selecting building materials and component assemblies required for the present study. Along with the materials and component assemblies, this chapter also identifies significant impact categories that account for environmental sustainability and incurred costs. Therefore, this section of the research is further divided into the following sub sections that focus on: (i) Selecting appropriate construction materials, (ii) analyzing possible component assemblies associated with the selected construction materials and (iii) investigating various impact categories and identifying the most significant ones from an environmental and cost perspective.

Selection of building materials, component assemblies can have a great impact on the project. In order to make a wise selection, careful analysis, like consideration of its complete life cycle and the associated impacts needs to be performed. The process of analysis can be difficult and hence an effective criteria-based evaluation is chosen. The following method of analysis performed (shown in figure 4).

(i) Identifying the purpose: The purpose of selecting a building material or a component assembly in this study is to use the alternatives for further analysis enabling the development of an evaluation tool.

(ii) Defining the criteria: In order to select, the following criteria needs to be addressed:

(a) Suitability to the project: With the growing interest in ecological and economic sustainability in building construction, the target system of a building now a day is its 
envelope. According to many researchers, a building envelope responds to both natural and human forces (WBDG). It functions as a protection to the interior spaces from the surrounding environment. Apart from protection, the enclosure elements is needed to provide the following functions:

- Support

- Control (Thermal, air and moisture)

- Aesthetic appearance (finishes)

- Distribution of Services (wherever required)

A building envelope includes the following elements of a building:
a. Below grade construction
b. Exterior Walls
c. Fenestration systems
d. Top covering floor of a building.

The major portion of a building envelope that experiences most exposure to the outside environment is the exterior wall and the top-covering floor of the building. Hence, the project in the present study is focused on constructing an exterior wall and roofs that attributes to the building envelope.

Exterior Walls: Exterior walls are a major component constituting a building enclosure. A well-designed and constructed wall can be responsible for good interior quality, thus mitigating the negative impacts on the health of the occupants. With proper choice of materials and an effective construction system, the above-mentioned functional benefits can be achieved.

Elements of a Building Wall: 
A typical building wall consists of the following elements:

1. Structural element

2. Insulating element and

3. Finishing surface

Building Roofs: The exterior surface and its supporting structure on the top of any building structure is the Roof. It is as equally responsible as the exterior wall in protecting the building and its interior from the adverse effects of the weather. The following are the elements of a building roof:

1. Supporting structure

2. Insulating element and

3. Uppermost weatherproof layer.

(b) Commonly used: Though there are many alternatives available in the market today, not all are in use in today's construction industry. There have been only few that are widely used due to its durability, aesthetic appearance and cost. For the purpose of this study only commonly used alternative, analyzing upon which, a comparative analysis with its counter-form of sustainability can be justified.

(c) Data availability: For researchers to conduct a comprehensive analysis, both quality and availability of data is very important. The challenges that can be faced while deriving the data are: (a) Accessibility, (b) Relevancy, (c) Accuracy and (d) Format of availability (Ge, 2007).

(iii) Composing Set of Alternatives: Will all possible choices, regardless of satisfying or not satisfying all of the above-mentioned set criteria, a group of choices is formed. While looking upon choices, two of its forms are to be identified; original and sustainable form. 
(iv) Rank the alternatives: Based on the level of satisfying the given criteria, a chronology of all the choices is made.

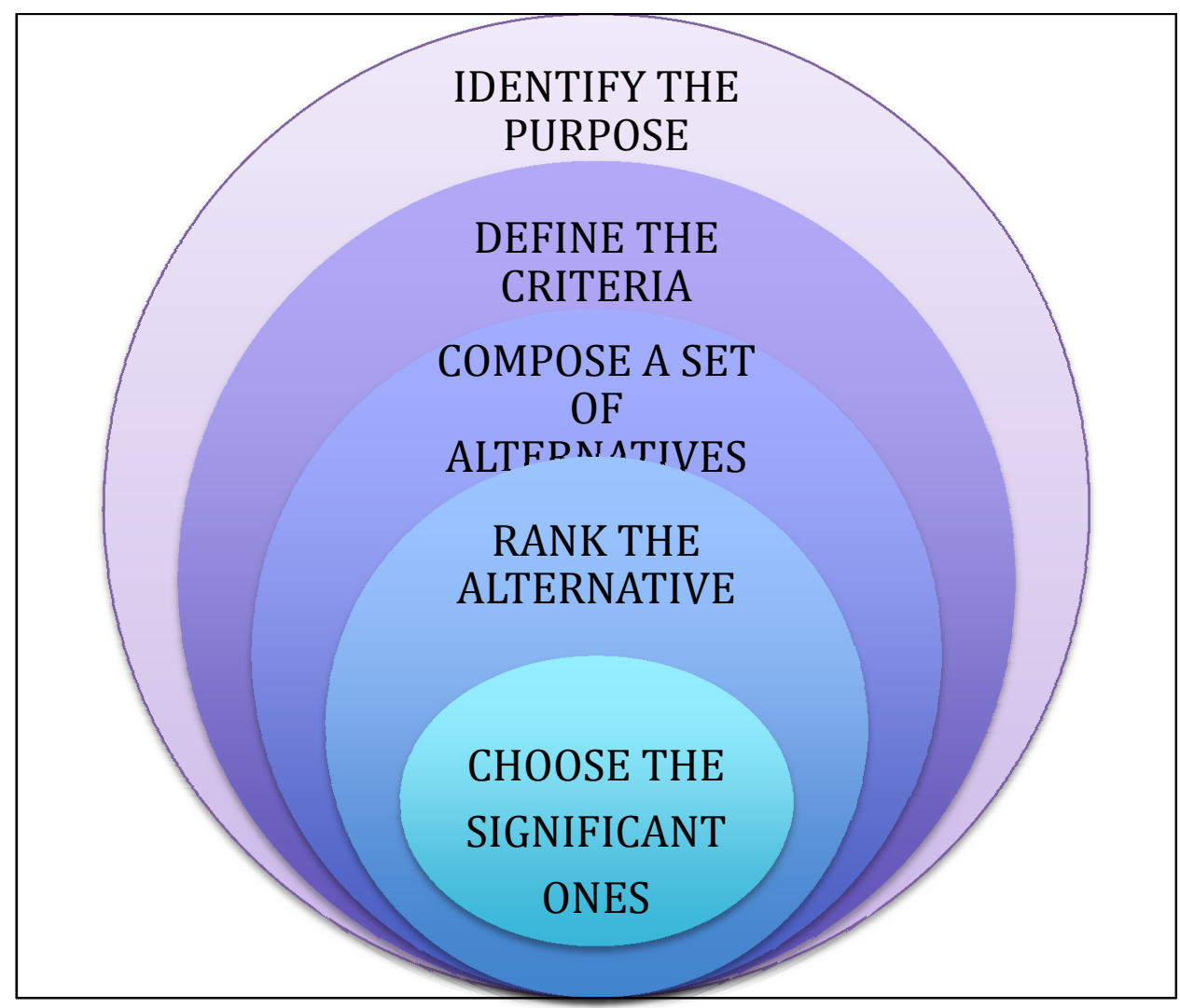

\section{Figure 3-1: Selection Analysis}

(v) Choosing the final set of alternatives: Based on the above ranking, the high-scored alternatives are chosen. This final set of alternatives is further analyzed and used as an aid for the development of the final evaluation tool.

Furthermore, collecting all the data required for the analysis is a very crucial step, as the quality of the results determined is importantly based on this. The scope of this research is limited to the existing databases that can be used for further analysis. Two of the databases; BEES 4.0 and ATHENA, is intended to be used in the present study. In addition to the above databases RS Means and available literature on previous studies are also considered as a source of data. 


\subsection{Construction Materials}

As mentioned in the previous section, construction industry is the largest consumer of materials (USGBC, 2002). Among a variety of construction materials available, the most largely used are crushed rock, sand, cement, asphalt, wood, clay, steel, aluminum, plastics etc. In order to select the significant ones, the materials are screened through the criteria described in section 3.1.

Purpose: The purpose of selecting a material is to construct the building component providing durability and improved quality to the building.

Suitability to the project: In this study, the scope of the project is limited to building exterior walls and roof, as mentioned earlier. The following is the classification of detailed elements that associate with the construction of exterior wall and roofs:

Table 3-1: Classification of elements of Building Components

\begin{tabular}{|l|l|}
\hline \multicolumn{2}{|c|}{ Elements of the Building Component } \\
\hline \multicolumn{1}{|c|}{ Building Exterior Walls } & \multicolumn{1}{c|}{ Building Roofs } \\
\hline Structural element & Supporting structure \\
\hline Insulating element (Optional) & Insulating element (Optional) \\
\hline Finishing surface & Uppermost weatherproof layer \\
\hline
\end{tabular}

Commonly used: With the classification of the required elements of the building component, studied in the present research, table 3-1 shows the list of most-commonly used materials in the construction of the classified elements, obtained through a detailed survey of local sources.

Data availability: As mentioned earlier, with the four challenges associated with the data availability, the materials are assessed accordingly. Even though data for the required subject is available, to enable a detailed analysis, these four challenges needs to be 
addressed. Hence, a screening through the challenges will give us the final set of alternatives that can be used. Table 3-3 is a tabular form that shows which alternatives have satisfied the said challenges.

Table 3-2: Commonly used materials.

\begin{tabular}{|c|c|c|c|}
\hline $\begin{array}{l}\text { Element } \\
\text { Component }\end{array}$ & $\begin{array}{c}\text { Structural } \\
\text { Support }\end{array}$ & $\begin{array}{c}\text { Insulating } \\
\text { Element }\end{array}$ & $\begin{array}{c}\text { Outermost } \\
\text { Layer }\end{array}$ \\
\hline Exterior Wall & $\begin{array}{l}\text { - } \text { Stone } \\
\text { - Clay brick } \\
\text { - } \text { Concrete Block } \\
\text { - Cast-in-place } \\
\text { - } \text { concrete } \\
\text { - Steel } \\
\text { - } \text { Wood } \\
\text { PVC }\end{array}$ & $\begin{array}{ll}\text { - } & \text { Perlite } \\
\text { - } & \text { Styrofoam } \\
\text { - } & \text { Polysterene } \\
\text { - } & \text { Fiber plank } \\
\text { - } & \text { Fiberglass } \\
\text { - } & \text { Pre-engineered } \\
& \text { steel }\end{array}$ & $\begin{array}{ll}\text { - } & \text { Stone Veneer } \\
\text { - } & \text { Clay Brick } \\
& \text { Veneer } \\
\text { - } & \text { Concrete } \\
& \text { Veneer } \\
\text { - } & \text { Cast-in-place } \\
\text { concrete } \\
\text { - Stucco } \\
\text { - Aluminum } \\
\text { siding } \\
\text { - Steel Siding } \\
\text { - } \text { Wood siding } \\
\text { - } \text { Vinyl siding } \\
\text { - Structural } \\
\text { - Insulated Panel } \\
\text { - EIFS } \\
\end{array}$ \\
\hline Roof & $\begin{array}{ll}\text { - } & \text { Cast-in-place } \\
& \text { concrete } \\
\text { - } & \text { Pre cast concrete } \\
\text { - } & \text { Steel } \\
\text { - } & \text { Wood }\end{array}$ & $\begin{array}{ll}\text { - } & \text { Polysterene } \\
\text { - } & \text { Urethane } \\
\text { - } & \text { Fiberglass } \\
\text { - } & \text { Cellulose fiber } \\
\text { - } & \text { Perlite }\end{array}$ & $\begin{array}{ll}\text { - } & \text { Asphalt } \\
& \text { Shingles } \\
\text { - } & \text { Wood Shingles } \\
\text { - } & \text { Steel } \\
\text { - } & \text { Aluminum tile } \\
\text { - } & \text { Clay tile } \\
\text { - } & \text { Concrete tile }\end{array}$ \\
\hline
\end{tabular}

Table 3-3: Screening through challenges with Data Availability (Exterior Walls)

\begin{tabular}{|lcccc|}
\hline \multicolumn{1}{|c}{ COMMONLY USED } & \multicolumn{3}{c|}{ DATA AVAILABILTY } \\
MATERIALS & ACCESSIBILTY & RELEVANCY & ACCURACY & $\begin{array}{l}\text { REQUIRED } \\
\text { FORMAT }\end{array}$ \\
\hline STRUCTURAL ELEMENT & & & & \\
\hline Stone & $\square$ & $\square$ & $\square$ & $\square$ \\
Clay brick & $\square$ & $\square$ & $\square$ & $\square$ \\
\hline
\end{tabular}




\begin{tabular}{|l|c|c|c|c|}
\hline \multicolumn{1}{|c|}{ COMMONLY USED } & $\begin{array}{c}\text { DATA } \\
\text { AVAILABILTY }\end{array}$ & & & \\
\hline MATERIALS & ACCESSIBILTY & RELEVANCY & ACCURACY & $\begin{array}{c}\text { REQUIRED } \\
\text { FORMAT }\end{array}$ \\
\hline Cast in place concrete & $\square$ & $\square$ & $\square$ & $\square$ \\
\hline Steel & $\square$ & $\square$ & $\square$ & $\square$ \\
Wood & $\square$ & $\square$ & $\square$ & $\square$ \\
PVC & $\square$ & $\square$ & $\square$ & $\square$ \\
& $\square$ & $\square$ & $\square$ & $\square$ \\
\end{tabular}

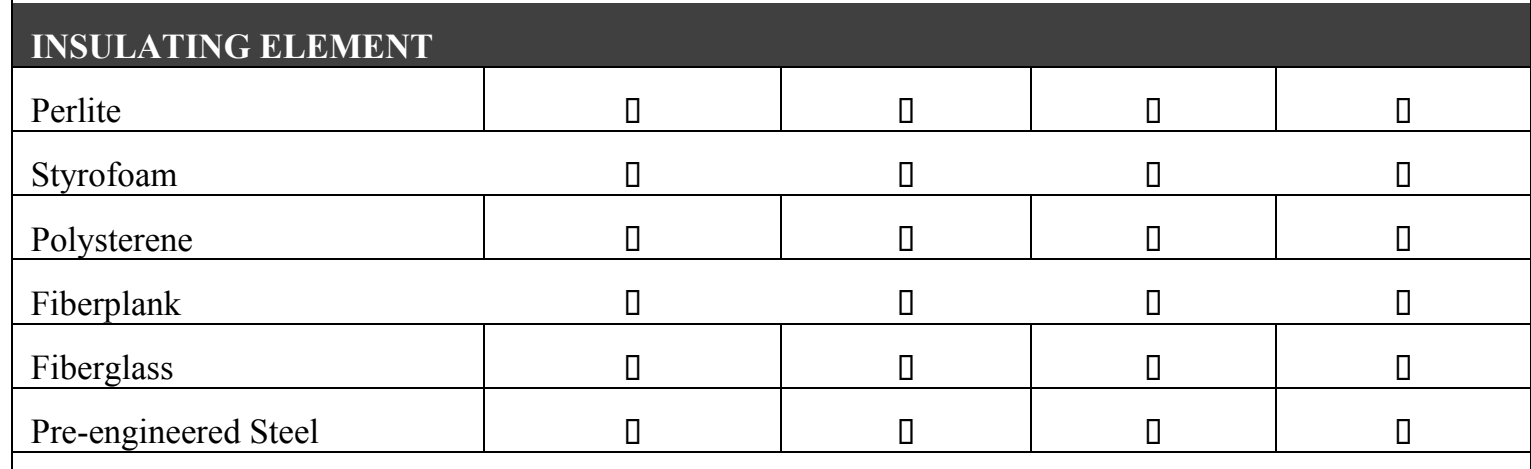

\begin{tabular}{|l|c|c|c|c|}
\hline FINISHING SURFACE \\
\hline Stone Veneer & $\square$ & $\square$ & $\square$ & $\square$ \\
\hline Clay Brick Veneer & $\square$ & $\square$ & $\square$ & $\square$ \\
\hline Concrete Veneer & $\square$ & $\square$ & $\square$ & $\square$ \\
\hline Cast-in-place Concrete & $\square$ & $\square$ & $\square$ & $\square$ \\
\hline Stucco & $\square$ & $\square$ & $\square$ & $\square$ \\
\hline Aluminum Siding & $\square$ & $\square$ & $\square$ & $\square$ \\
\hline Steel Siding & $\square$ & $\square$ & $\square$ & $\square$ \\
\hline Wood Siding & $\square$ & $\square$ & $\square$ & $\square$ \\
\hline Vinyl Siding & $\square$ & $\square$ & $\square$ & $\square$ \\
\hline SIP & $\square$ & $\square$ & $\square$ & $\square$ \\
\hline EIFS & $\square$ & $\square$ & $\square$ & $\square$ \\
\hline
\end{tabular}

The above table 3-3 shows that all of the materials listed satisfy the given criteria of data availability. In the further proceeding of the analysis, it is very important to know what type of data is available from the preferred sources. As mentioned earlier, within 
this research the analysis had to be done with available databases. So, as a proceeding to choosing the alternatives for the analysis, a screening through BEES and ATHENA is carried out. Proper representation of screening is shown in Table 3-4.

TABLE 3-4: SCREENING MATERIALS THROUGH AVAILABILITY OF DATA SOURCES (EXTERIOR WALLS)

\begin{tabular}{|c|c|c|c|c|c|}
\hline 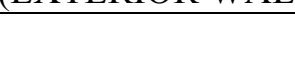 & DAT & OURCES A & AILABLE & & SELECTED \\
\hline $\begin{array}{l}\text { MATERIALS } \\
\text { FROM TABLE 3-3 }\end{array}$ & BEES & ATHENA & RS MEANS & LITERATURE & MATERIALS \\
\hline STRUCTURAL EI & MENT & & & & \\
\hline STONE & & & П & & \\
\hline CLAY BRICK & & & П & П & \\
\hline CONCRETE & & & & & \\
\hline $\begin{array}{l}\text { BLOCK } \\
\text { CAST-IN-PLACE }\end{array}$ & & प & प & Q & \\
\hline $\begin{array}{l}\text { CAST-IN-PLACE } \\
\text { CONCRETE }\end{array}$ & & Q & Q & प & \\
\hline STEEL & Q & Q & प & 0 & STEEL \\
\hline WOOD & प & प & Q & प & WOOD \\
\hline PVC & & & ૫ & & \\
\hline INSULATING ELI & ENT & & & & \\
\hline PERLITE & & & प & & \\
\hline STYROFOAM & & & 0 & & \\
\hline POLYSTERENE & & Q & 0 & & \\
\hline FIBER PLANK & & & प & & \\
\hline FIBERGLASS & प & प & प & प & FIBERGLASS \\
\hline $\begin{array}{l}\text { PRE- } \\
\text { ENGINEERED } \\
\text { STEEL }\end{array}$ & & & Q & & \\
\hline FINISHING SURF & & & & & \\
\hline STONE VENEER & & 口 & 口 & & \\
\hline $\begin{array}{l}\text { CLAY BRICK } \\
\text { VENEER }\end{array}$ & प & प & प & प & $\begin{array}{c}\text { CLAY BRICK } \\
\text { VENEER }\end{array}$ \\
\hline $\begin{array}{l}\text { CONCRETE } \\
\text { VENEER } \\
\text { CAST-IN-PLACE } \\
\text { CONCRETE }\end{array}$ & & & प & प & \\
\hline STUCCO & प & Q & Q & Q & STUCCO \\
\hline $\begin{array}{l}\text { ALUMINUM } \\
\text { SIDING }\end{array}$ & Q & & प & प & \\
\hline
\end{tabular}


DATA SOURCES AVAILABLE

\begin{tabular}{|c|c|c|c|c|c|}
\hline \multicolumn{5}{|c|}{ DATA SOURCES AVAILABLE } & \multirow{2}{*}{$\begin{array}{l}\text { SELECTED } \\
\text { MATERIALS }\end{array}$} \\
\hline $\begin{array}{l}\text { MATERIALS } \\
\text { FROM TABLE 3-3 }\end{array}$ & BEES & ATHENA & RS MEANS & LITERATURE & \\
\hline WOOD SIDING & Q & 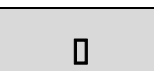 & 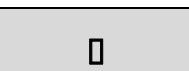 & 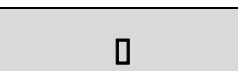 & WOOD SIDING \\
\hline VINYL SIDING & Q & Q & Q & प & VINYL SIDING \\
\hline ST. IN. PANELS & Q & & Q & & \\
\hline EIFS & Q & $\square$ & Q & $\square$ & EIFS \\
\hline
\end{tabular}

The materials that has the data available in the required format in all the four categories are hence shortlisted as following:

Exterior wall Structural Element:

- Steel

- Wood

Exterior wall insulating element:

\section{- Fiberglass}

Exterior wall finishing surface:

- Clay brick Veneer

- Stucco

- Wood Siding

- Vinyl Siding

\section{- Exterior Insulated Finish systems (EIFS)}

Similarly, to be able to analyze the materials used in a roof construction, the selection is made after thorough screening against the criteria set and as mentioned earlier in this study. Table 3-5 is the selection of materials through the challenges associated with the data availability. 


\begin{tabular}{|c|c|c|c|c|}
\hline \multirow{2}{*}{$\begin{array}{c}\text { COMMONLY USED } \\
\text { MATERIALS }\end{array}$} & \multicolumn{4}{|c|}{ DATA AVAILABILTY } \\
\hline & ACCESSIBILTY & RELEVANCY & ACCURACY & FORMAT \\
\hline \multicolumn{5}{|l|}{ STRUCTURAL ELEMENT } \\
\hline Cast-in-place Concrete & Q & Q & & \\
\hline Pre-cast concrete & $\square$ & 0 & & \\
\hline Steel & प & Q & 0 & Q \\
\hline Wood & Q & Q & Q & Q \\
\hline \multicolumn{5}{|l|}{ INSULATING ELEMENT } \\
\hline Polystyrene & $\square$ & 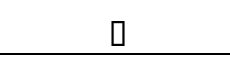 & Q & $\square$ \\
\hline Urethane & Q & प & & \\
\hline Fiberglass & $\square$ & Q & 0 & Q \\
\hline Cellulose fiber & Q & Q & & \\
\hline Perlite & Q & Q & Q & Q \\
\hline \multicolumn{5}{|l|}{ ROOF COVERING } \\
\hline Asphalt Shingles & $\square$ & Q & 0 & Q \\
\hline Wood Shingles & Q & Q & Q & Q \\
\hline Steel & Q & Q & 0 & Q \\
\hline Aluminum Tile & Q & 0 & 0 & $\square$ \\
\hline Clay Tile & Q & Q & Q & Q \\
\hline Concrete Tile & $\square$ & 口 & 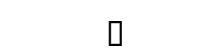 & $\square$ \\
\hline
\end{tabular}

Table 3-5: Screening materials through challenges with Data Availability (Roofs)

From the set of materials that have all cleared the challenges defined, further screening as a step towards selecting a final set of alternatives is shown in table 3-6.

Table 3-6: Screening materials through availability of data sources (roofs)

\begin{tabular}{|l|c|c|c|c|}
\hline $\begin{array}{c}\text { MATERIALS FROM } \\
\text { TABLE 3-5 }\end{array}$ \\
\begin{tabular}{|l|c|c|c|} 
DATA SOURCES AVAILABLE \\
SELECTED
\end{tabular} \\
STRUCTUAL ELEMENT & ATHENA & RS MEANS & LITERATURE & MATERIALS \\
\hline STEEL & $\square$ & 0 & & STEEL \\
\hline
\end{tabular}




\begin{tabular}{|c|c|c|c|c|c|}
\hline \multicolumn{5}{|c|}{ DATA SOURCES AVAILABLE } & \multirow{2}{*}{$\begin{array}{r}\text { SELECTED } \\
\text { MATERIALS } \\
\end{array}$} \\
\hline $\begin{array}{c}\text { MATERIALS FROM } \\
\text { TABLE 3-5 } \\
\end{array}$ & BEES & ATHENA & RS MEANS & LITERATURE & \\
\hline \multicolumn{6}{|c|}{ INSULATING ELEMENT } \\
\hline \multicolumn{6}{|l|}{ POLYSTERENE } \\
\hline FIBERGLASS & & Q & Q & & FIBERGLASS \\
\hline PERLITE & & & 0 & & \\
\hline \multicolumn{6}{|l|}{ ROOF COVERINGS } \\
\hline $\begin{array}{l}\text { ASPHALT } \\
\text { SHINGLES }\end{array}$ & Q & Q & प & & $\begin{array}{l}\text { ASPHALT } \\
\text { SHINGLE }\end{array}$ \\
\hline \multicolumn{6}{|l|}{ WOOD SHINGLES } \\
\hline STEEL & & Q & 0 & & \\
\hline \multicolumn{6}{|l|}{ ALUMINUM TILE } \\
\hline CLAY TILE & Q & Q & Q & & CLAY TILE \\
\hline CONCRETE TILE & & & $\mathrm{Q}$ & & \\
\hline
\end{tabular}

The materials that has the data available in the required format in all the four

categories are hence shortlisted as following:

Roof Structural Element:

- Steel

- Wood

Roof insulating element:

\section{- Fiberglass}

Roof covering:

\section{- Asphalt Shingles}

\section{- Clay tiles}

With all the screening performed on the materials used for building exterior walls and roofs, the following is the final set of alternatives with its specifications that is used for further analysis. 


\section{Exterior Wall Materials:}

- Steel framing: The steel in general is preferred as a supporting element because of its advantageous fire-resistance characteristics. It is also easy to install utilities into it along with ease of erecting the support. The steel that is used for analysis has the following specifications:

○ 33 mil galvanized steel studs

○ Steel screws included $(0.0056 \mathrm{~kg})$

○ Placed at $24 "$ on center.

- Functional unit $=1$ Sq. Ft.

- Wood framing: The wood framing used in the present study has the following specifications:

○ 1.5 " wooden studs

$\circ \quad$ Galvanized steel nails $(0.04 \mathrm{~kg})$

- Placed at 16 " on center

$\circ$ Functional unit= 1 Sq. Ft.

- Fiberglass insulation: The fiberglass used as an insulating element in the construction of the exterior wall has the specifications as below:

○ Thermal resistance $=\mathrm{R} 13$

○ 3.5" Thickness

○ Approximately $1.07 \mathrm{~kg} / \mathrm{sft}$

$\circ$ Functional unit $=1$ Sq. Ft

- Clay brick wall finish: The clay brick in the analysis considers not only brick but also the mortar used to bind the clay bricks together. Their specifications are: 
○ Brick size used is $7.62 " \times 2.2 " \times 3.6 "$

- In one unit of the wall, the ratio of brick and mortar by volume is $4: 1$ respectively

- The mortar considered is Type $\mathrm{N}$ with density $115 \mathrm{lb} / \mathrm{sft}$

- Functional unit= 1 Sq. Ft.

- Stucco finish: the types of cement that are used most commonly are Portland cement and masonry cement. In order to give more choice to the decision-makers, the analysis here considers the average of both Portland cement and masonry cement. The functional unit being $1 \mathrm{Sq}$. Ft.

- Wood Siding: Wood siding is used as the exterior wall finish as it is lightweight, has low density, appears aesthetically pleasant and also provides adequate weatherproofing. Following are the specifications:

○ 6" wide and $1 / 2 "$ thick siding panels

Functional unit $=1 \mathrm{Sq} . \mathrm{Ft}$

- Analysis also considers 3 Galvanized nails.

- Vinyl Siding: The analysis of vinyl siding considers the following:

○ Functional unit $=1 \mathrm{Sq} . \mathrm{Ft}$

○ 9" wide and 0.042 " thick siding panels

- Galvanized nail fastners included.

- Exterior Insulated Finish Systems: RPM Intl, OH manufactures he EIFS system considered in this database. It consists of expanded polystyrene (EPS), insulation board, fiberglass mesh; cement based adhesive, polymer-based textured finish. Functional unit=1 Sq. Ft. 


\section{Roof Coverings:}

- Asphalt Shingles: The size of each shingle considered in this study is 12 " x 36 ". It considers roofing underlayment and galvanized steel nails also. Functional unit studied $=1$ Sq. Ft.

- Clay tiles: The clay tiles studied is considered along with the roofing felt and galvanized nails and the functional unit being $1 \mathrm{Sq}$. Ft. 


\subsection{Building component assemblies}

The components of a building, for example: foundations, walls, floors, roofs, etc., can be built in a number of ways. Before selecting the final set of alternatives, below are the preliminary criteria fulfillment associated with the building component assemblies.

Purpose: The purpose of selecting the type of component assembly is to construct the building component with more efficiency and with more insight towards environmental sustainability.

Suitability to the project: With the scope of the study being limited, the types component assemblies used in the construction of exterior walls and roofs only are considered.

Commonly used: With the wide options available, the following table gives an insight about the most commonly preferred component assemblies:

Table 3-7: Screening component assemblies through challenges with data availability

\begin{tabular}{|c|c|c|c|c|}
\hline \multirow{2}{*}{$\begin{array}{c}\text { COMMONLY USED } \\
\text { ASSEMBLIES }\end{array}$} & \multicolumn{4}{|c|}{ DATA AVAILABILTY } \\
\hline & ACCESSIBILTY & RELEVANCY & $\begin{array}{l}\text { ACCURAC } \\
\text { Y }\end{array}$ & $\begin{array}{l}\text { REQUIRED } \\
\text { FORMAT }\end{array}$ \\
\hline \multicolumn{5}{|l|}{ EXTERIOR WALLS } \\
\hline Cast-in-place Concrete & ૫ & प & प & प \\
\hline Pre-fabricated concrete & Q & प & प & प \\
\hline Masonry & Q & Q & Q & प \\
\hline Built-up & प & Q & Q & Q \\
\hline Cavity & प & प & प & प \\
\hline Composite & Q & प & प & प \\
\hline \multicolumn{5}{|l|}{ ROOFS } \\
\hline Cast-in-place concrete & प & प & & \\
\hline Pre-fabricated concrete & प & प & & \\
\hline Built-up & Q & Q & Q & Q \\
\hline
\end{tabular}


Data availability: With the four challenges associated with the data availability, the above table also shows the components that are screened accordingly. A step further involves screening through the availability of data from four of the sources is performed.

Table 3-8: Screening assemblies through availability of data sources.

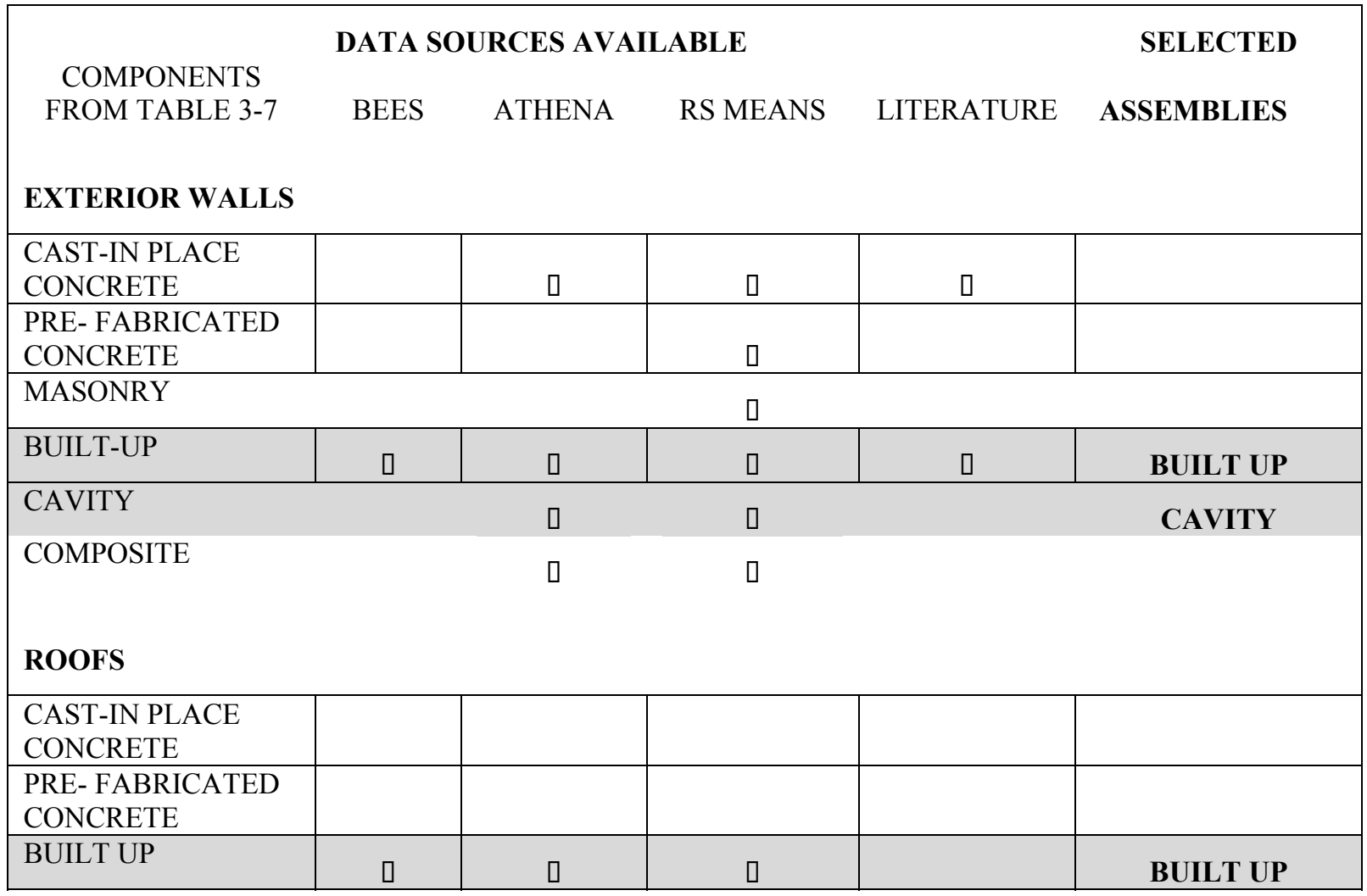

After the screening process, the final set of component assemblies that has the data available in the required format in all the four categories are shortlisted as following: Exterior walls:

- Built-up wall

- Cavity Wall

Roofs:

\section{- Built-up roof}


A more detailed specification of each kind of component assembly that is selected is presented as follows:

Exterior Built-up Wall: Built-up wall is a term that is commonly used to describe an exterior wall system of assembly that basically works to have weather-tightness of the outermost exterior wall surfaces and construction joints in order to keep the rainwater penetration at the minimal. This type of wall system is commonly built with precast concrete panels, composite and solid metal plate exterior cladding systems, exterior insulation and finish systems (EIFS), etc. This system is considered cost-effective and therefore preferred over cavity or mass walls assemblies. In constructing built-up walls it should be of a concern that they: a) offer only a single line of defense against rainwater penetration; b) often include relatively complex interface details that require a level of workmanship in the field, and; c) require a routine maintenance to remain effective in the long term, resulting in increased long-term maintenance costs. The figure below shows a typical built-up wall that can be associated with varying combinations of structural and finishing surfaces.

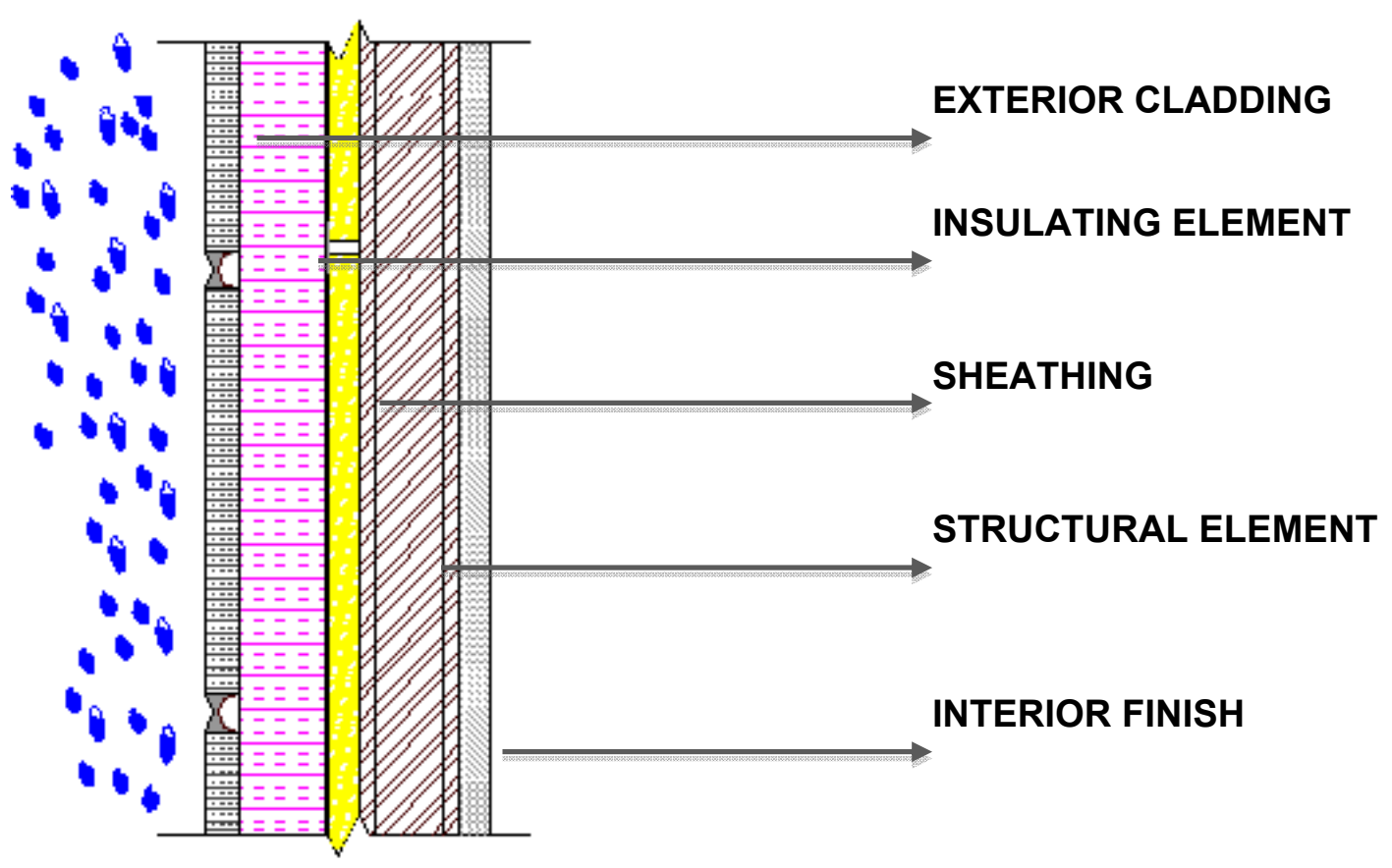

Figure 3-2: Built-up Wall 
Exterior Cavity Wall: In United States, cavity walls are preferred mode of construction in climatic and rainfall zones. This is because this wall can resist uncontrolled, bulk rainwater penetration. Cavity walls commonly use clay brick and/or concrete masonry wall systems built over an open unobstructed air space/ cavity. The cavity can be partially or fully concealed air space that resists the rainwater penetration and based on the way it is designed, it can also improve the overall thermal insulation between building's exterior and interior environment. The figure shown below represents a typical cavity wall:

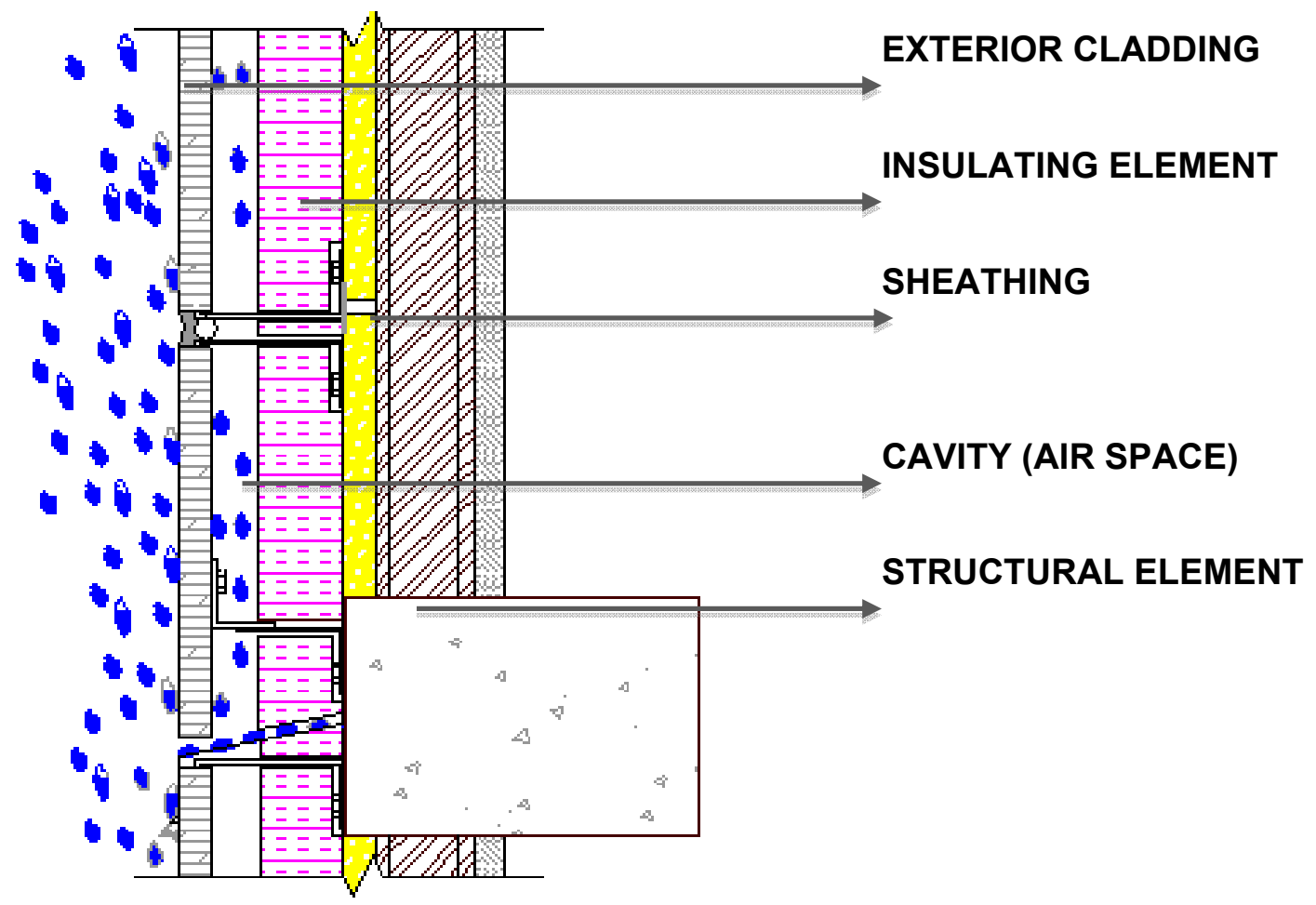

Figure 3-3: Cavity Wall

Built-up Roof assembly: Built up roofs is one of the oldest and most common roofing systems. This is called by this name as it is made up of successive layers of decking, felts, insulations and coverings. A built-up roof, as any other roofing systems is prone to leakages when maintained poorly. The key factor behind longer life span of a built up 
roof is well maintenance. Shown below is the construction of the built-up roof:

Figure 3-4: Built up Roof

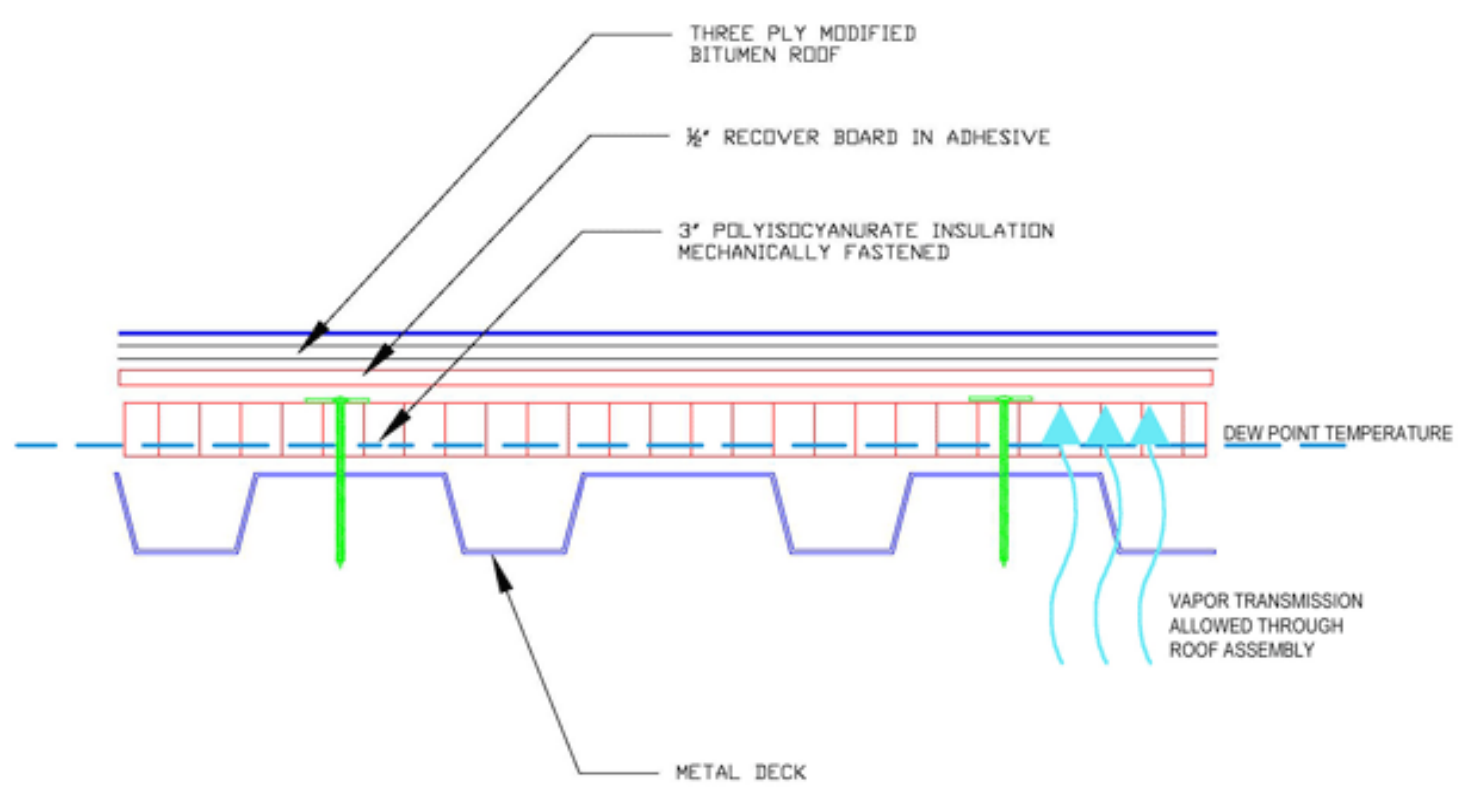

\subsection{Impact indicators}

As mentioned in the previous sections, construction industry is responsible for a major percentage of the environmental impacts produced, mostly in the developed countries (UNEP, 2003). Being one of the most active sectors all over the world, according to UNEP (2003), the construction industry is also the largest industrial employer, accounting up to $7 \%$ of the total employment and $28 \%$ of industrial employment. On the other hand, the construction sector is responsible for a high rate of energy consumption, environmental impacts and resource depletion (NBT, 2009).

Impacts of building materials production and construction on the environment fluctuate hugely based on the region where they take place. When highly developed nations and low-income countries are compared, it is indicated that low-income countries usually have less efficient processes that will require more energy and at the same time produce 
more environmental impacts (Buchanan, 1994; Harris, 1999; Emmanuel, 2004; Asif et al, 2007).

Apart from this, energy production processes differ between countries and even regions, for example: electricity production could derive mainly from hydropower or nuclear or thermal plants that generate drastically various environmental impacts (Cole, 1999). Considering such factors, it becomes quite impossible to use the same values of energy consumption and/ or environmental impacts for a given material in different contexts. Harris (1999) suggests on expressing various indicators of impacts separately for the same material or component, as very bad ones observing one indicator might accompany good results in another indicator. In this context, Huberman and Pearlmutter (2008) in their study observed that the use of single point indicators (such as energy) to assess environmental impacts might not represent all required environmental aspects but they can be easier to understand. The same authors have used $\mathrm{CO}_{2}$ emissions, based on primary energy consumption, as a prime indicator of environmental impact because of its importance in global warming and because energy efficiency is an indicator of a building's overall resource efficiency. To its addition, Buchanan and Honey (1994) consider that, among the various greenhouse gases emitted by human activities, $\mathrm{CO}_{2}$ is the most important by-product of the manufacturing of building materials.

Energy consumption and the amount of building materials to be transported can also be used for expressing environmental impacts of building construction (Morel et al., 2001). However, it can be said from the previous observations that though the use of energy is more or less directly connected to environmental pressure in many aspects and has also proven to affect many of the environmental impact categories, some of the 
impacts are not directly influenced by energy consumption. In another study by Svensson et al. (2006), it is indicated that energy indicator provides strong to moderate reflection of environmental impacts for the following categories: depletion of fossil fuels (as a resource), climate change, toxicity aspects, acidification and waste heat, unlike the following categories that are weakly reflected by the energy indicator: depletion of minerals, metals and other abiotic as well as biotic resources, impact of land use, stratospheric ozone depletion, photo-oxidant formation, eutrophication, odor, noise, ionizing radiation, causalities.

After reviewing all the existing literature on various types of environmental impact indicators, the most commonly studied impact indicators are represented in the following form of categories:

- Atmospheric emissions

- Global Warming Potential

○ Health quality

- Acidification Potential

○ Eutrophication Potential

- Waste generation

○ Solid wastes

- Water wastes

- Resource Consumption

○ Water consumption

○ Energy consumption

- Raw materials consumption 
○ Fuel consumption

- Cost incurred

- First costs

○ Future costs

As per the set criteria, these common impacts of building construction are tested on the level of satisfying, as properly represented in the following table 3-9:

Table 3-9: Screening impact indicators through challenges with data availability

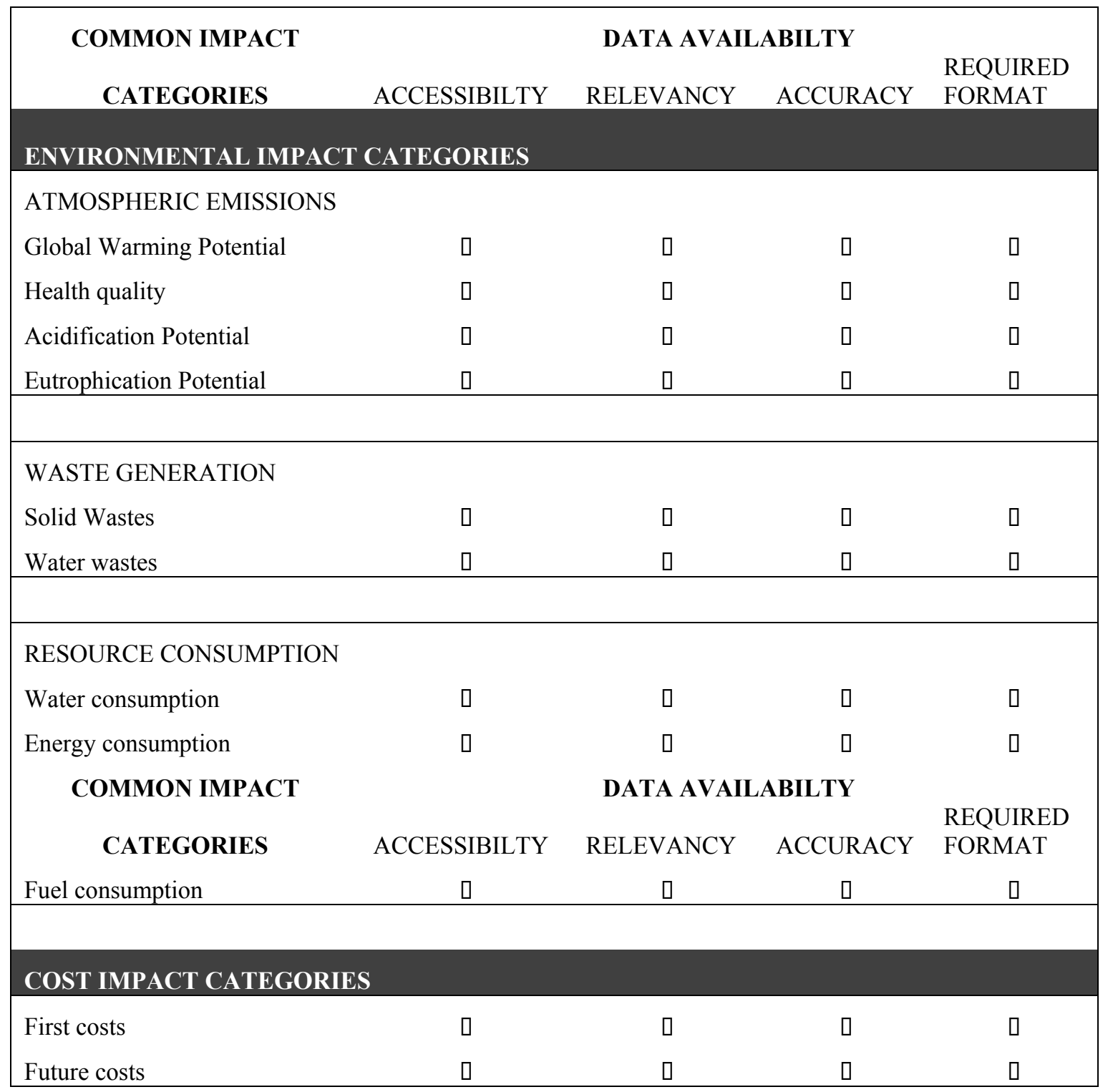


Further analysis of these impacts requires to be screened through the criteria set up in the previous section. This is well represented in the tabular form as below:

Table 3-10: Screening impact indicators through availability of data sources.

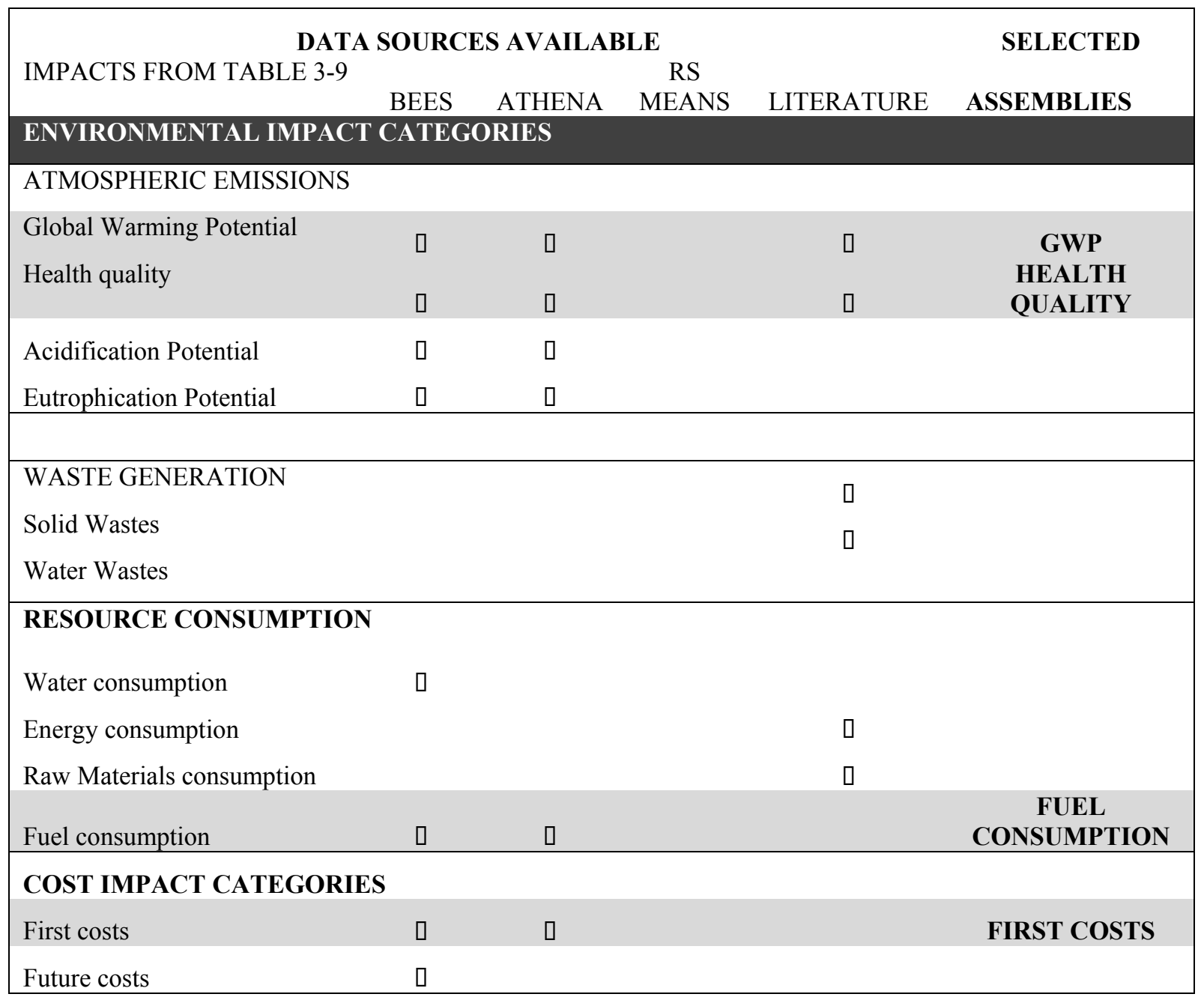

The final set of impact indicators and its details that will be further studied in the following chapters are:

- Global Warming Potential: Global Warming is the consequence of long-term build up of greenhouse gases $\left(\mathrm{CO}_{2}, \mathrm{CH}_{4}, \mathrm{~N}_{2} \mathrm{O}\right.$, etc. $)$ in the higher layer of atmosphere. The emission of these gases is the result of intensive environmentally harmful human activities such as the burning of fossil fuels, deforestation and 
land use changes (Buchanan, 1994). Therefore, the Global Warming Potential can be said as the estimated amount of greenhouse gases created. This is measured in Mass Units of Carbon dioxide equivalents.

- Health Quality: Health quality is defined by means of the quality of air. It is a measure of the condition of air relative to the requirements of any human need or purpose. It is the amount of airborne particles estimated that can lead to asthma, bronchitis, acute pulmonary diseases, etc. It is measured in mass units of particulate matter in the air.

- Fuel Consumption: The fossil fuel consumption is estimated by the amount of fossil fuel energy used in the extraction, processing, transportation, construction and disposal of each material. This is measure in Mega joules (MJ).

- First costs: First costs in the present study indicates the costs incurred with the purchase and installation of the product. This is evaluated over a fixed period of time and the measurement is quite straightforward when compared to the environmental performance. There are many published economic data available. RS Means is the prime source of data for collecting the performance values. The first costs are measured in terms of currency (USD in the present study).

\subsection{Summary}

As mentioned earlier, in this study, it is beyond the scope to collect all data, which is randomly available. To be able to get the most appropriate form of data, existing databases were intended to use. Different databases take into account various impacts, materials and component assemblies under study. Hence a combination of various databases for obtaining the data for various categories was used. A final set of 
alternatives was obtained from a pool of choices available. These alternatives are hence assumed to be the most common, most effective and most studied categories. Following is the summary of the set of alternatives obtained:

Table 3-11: Set of Materials for exterior walls

\begin{tabular}{|l|l|l|}
\hline Structural element & Insulating element & Finishing Surface \\
\hline$\bullet$ Steel & $\bullet$ Fiberglass & $\bullet$ Clay brick veneer \\
& & $\bullet$ Stucco \\
& & $\bullet$ Wood siding \\
& & $\bullet$ Vinyl Siding \\
& & EIFS \\
\hline
\end{tabular}

Table 3-12: Set of Materials for Roofs

\begin{tabular}{|l|l|l|}
\hline Structural element & Insulating element & Roof covering \\
\hline$\bullet$ Steel & $\bullet$ Fiberglass & $\bullet$ Asphalt Shingles \\
$\bullet$ Wood & & $\bullet$ Clay tiles \\
\hline
\end{tabular}

Set 3: Exterior Wall component Assemblies

- Built up Walls

- Cavity Walls

Set 4: Impact indicators

- Global Warming Potential

- Health quality index

- Fuel consumption

- First costs

The following chapter will focus on analyzing the set of material alternatives for the associated impact indicators. 


\section{CHAPTER 4: OVERALL ENVIRONMENTAL IMPACT ASSESSMENT}

\subsection{Introduction}

There are various methods available for assessing the environmental impacts of materials and components with the building sector. Though the methods suffice to a specific purpose and to an extent, there still have noted disadvantages. Life Cycle Assessment (LCA) is one of the methodologies for evaluating the environmental loads of processes and products during their whole life cycle (Sonnermann, 2003). The meaning of LCA is the assessment of a product including its entire life cycle, process of extraction of raw materials, manufacturing, transportation \& distribution, use, re use, maintenance, recycling and final disposal (Consoli, 1993). The International Organization for Standardization (ISO) 14040 series describes four general steps to be performed in any Life-cycle assessment (LCA): goal and scope definition, inventory analysis, impact assessment and interpretation. The inventory analysis step requires the use of national or international databases or manufacturer-specific data that quantifies the inputs and outputs of systems. The U.S. Life-Cycle Inventory (LCI) Database is a commonly referred-to national database. The impact assessment step requires the application of assessment methodologies, such as the Environmental Protection Agency's (EPA) Tool for the Reduction and Assessment of Chemicals and other environmental Impacts (TRACI).

After a thorough study on available impact assessment methods, eco-indicator 99 was intended to use for this research. This method is transparent and expresses the environmental impacts in a way that is easily communicable. This is also the most commonly used method in many of the existing software. It is usually not advised to 
calculate a single score for the environmental effects but it was decided to the weighting and scoring anyways, proved a proper justification of the normalized scored. The main idea behind this was to improve communication. To analyze and give the weighted score to the set of alternatives in this research, the Building for Environmental and Economic Sustainability (BEES) 4.0 was used as the prime data source. Among many methods available, for supportive decision-making the following methods are widely used to solve the Multi-Criteria Decision making problems in construction industry: Analytic Hierarchy Process (AHP), Technique of Order Preferences by Similarity to Ideal Solution (TOPSIS), Elimination and Choice Expressing the Reality (ELECTRE) and Simple Multi-Attribute Rating Technique (SMART). TOPSIS has been adapted in this research to solve the MCDM problem. This is one the methods widely accepted among practitioners, as it is easily conceivable and its calculations can be simply performed (Schinas 2007). One of the greatest advantages of this technique is that it can use any weighted scale selected by the decision maker and it can use the same decision matrix. This technique is also capable of handling large number of alternatives, like the one in this research. The fundamental idea behind the TOPSIS method is that the chosen alternative will have the shortest distance from the ideal solution and farthest from the negative ideal solution (Hwang and Yoon, 1981; Schinas, 2007). The figure below shows the evaluation method followed in using the TOPSIS technique. 


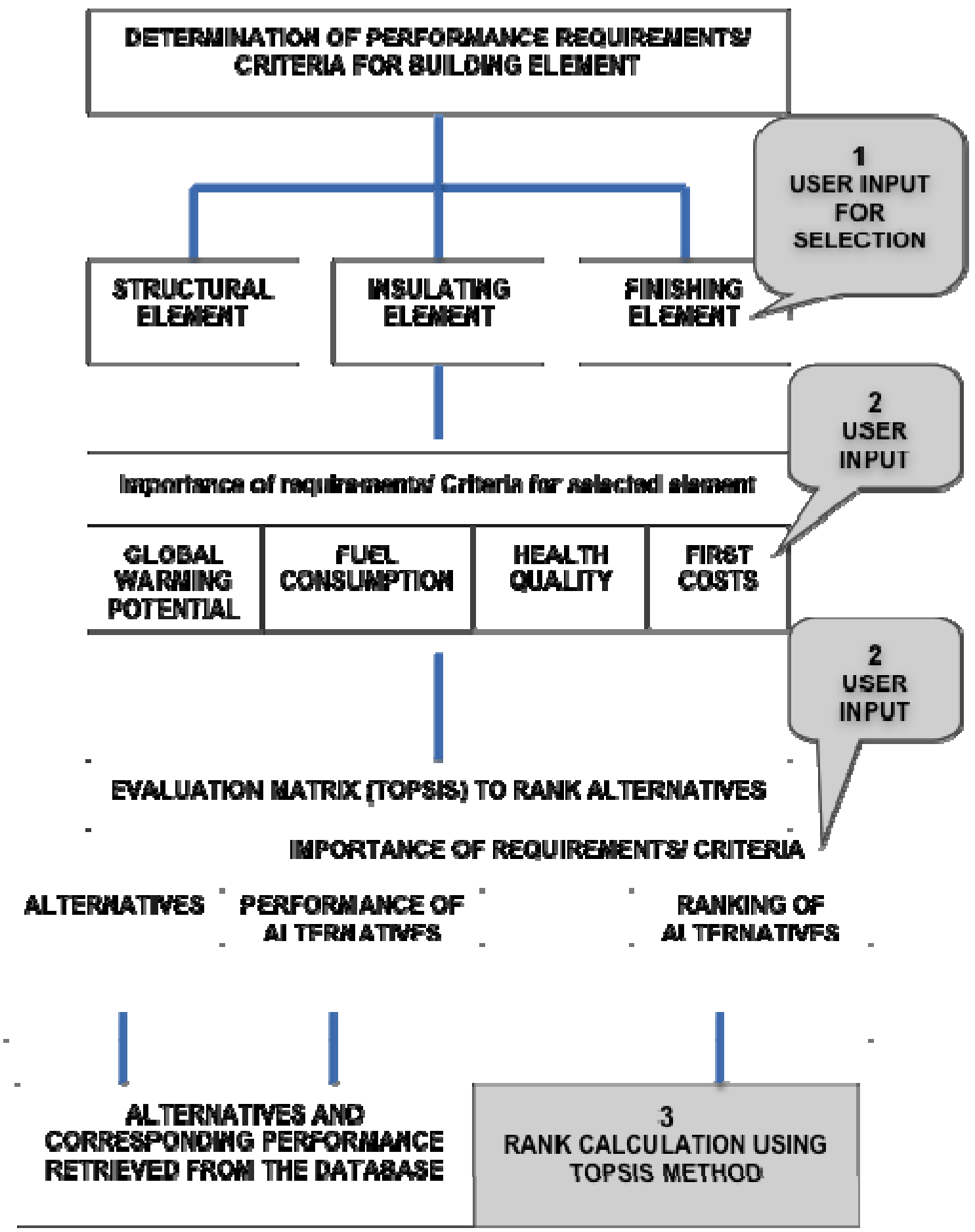

Figure 4-1: Qualitative evaluation for effective selection 
This process is used to select the best alternative of materials and component assembly of a building. The order of performance of this system is as follows:

1. The user selects the building element (Walls or Roofs) from the user selection input.

2. The user element by using ratio scale stated in Table 4-1.

Table 4-1: Ratio Scale/ Weighted Matrix for impact indicators (W)

\begin{tabular}{|c|c|c|c|}
\hline IMPACT & GWP & $\begin{array}{c}\text { HEALTH } \\
\text { QUALITY }\end{array}$ & $\begin{array}{c}\text { FUEL } \\
\text { CONSUMPTION }\end{array}$ \\
\hline WEIGHT & 2 & 2 & 1 \\
\hline
\end{tabular}

3. The performance of the materials of corresponding element is retrieved from the database. The evaluation and selection of materials and component assembly and ranking of alternatives are performed by TOPSIS. The detailed mathematical calculation is illustrated in the following section.

4. The materials and component assemblies are ranked by the system and the user may select the material and the type of component assembly. The system performs this process for each element and this can be saved in the project's database.

\subsection{Assessing environmental impacts of Materials}

Calculation of performance scores using TOPSIS:

Table 4-2: Performance of Alternatives

\begin{tabular}{|lrrr|}
\hline \multicolumn{1}{|c}{ MATERIAL/ } & \multicolumn{1}{c}{ GWP } & Health Quality & $\begin{array}{c}\text { FOSSIL FUEL } \\
\text { CONSUMPTION } \\
\text { ASSEMBLY }\end{array}$ \\
(Kg of CO & & & \\
(Micro DALY) & & 0.6014 \\
STEEL & 3.092 & 0.0027 & 0.2944 \\
WOOD & 1.449 & 0.0249 & \\
\hline
\end{tabular}




\begin{tabular}{|c|c|c|c|}
\hline $\begin{array}{l}\text { MATERIAL/ } \\
\text { ASSEMBLY }\end{array}$ & 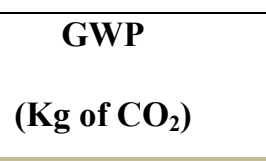 & $\begin{array}{l}\text { Health Quality } \\
\text { (Micro DALY) }\end{array}$ & $\begin{array}{c}\text { FOSSIL FUEL } \\
\text { CONSUMPTION } \\
\text { (MJ) }\end{array}$ \\
\hline BRICK \& MORTAR & 15.995 & 0.1066 & 7.9664 \\
\hline STUCCO & 3.615 & 0.0753 & 1.2094 \\
\hline WOOD SIDING & 8.371 & 0.0396 & 1.6485 \\
\hline VINYI SIDING & 7.553 & 0.027 & 3.49 \\
\hline EIFS & 3.320 & 0.0498 & 2.0775 \\
\hline ASPHALT & 5.304 & 0.1101 & 8.3772 \\
\hline CLAY TILE & 7.7075 & 0.0322 & 5.3391 \\
\hline
\end{tabular}

The next step is normalizing the scores of different impact indicators. The normalization values are obtained for each impact at the U.S. level using the Normalization Values as shown in Table 4-3:

TABLE 4-3: NORMALIZATION VALUES

\begin{tabular}{|l|c|}
\hline \multicolumn{1}{|c|}{ IMPACT } & NORMALIZATION VALUE \\
\hline Global Warming Potential & $25,582.64 \mathrm{~kg} \mathrm{CO}$ equivalents/ year/ capita \\
\hline Health Quality & $19,200.00 \mathrm{micro} \mathrm{DALY} /$ year/ capita \\
\hline Fossil fuel depletion & $35,309.00 \mathrm{MJ}$ surplus energy/ year/ capita \\
\hline
\end{tabular}

Therefore, using the normalization values we arrive at the Normalized Decision Matrix (R) for the selected set of alternatives by dividing the performance scores by normalization values: 
Table 4-4: Normalized Decision Matrix (R)

\begin{tabular}{|lcrc|}
\hline \multicolumn{1}{c}{$\begin{array}{c}\text { MATERIAL/ } \\
\text { ASSEMBLY }\end{array}$} & $\begin{array}{c}\text { GLOBAL } \\
\text { WARMING } \\
\text { POTENTIAL }\end{array}$ & HEALTH QUALITY & $\begin{array}{c}\text { FOSSIL FUEL } \\
\text { DEPLETION }\end{array}$ \\
STEEL & 0.0121 & 0 & 0.0017 \\
WOOD & 0.0060 & 0.0001 & 0.0008 \\
FIBERGLASS & 0.0014 & & 0.0006 \\
BRICK \& MORTAR & 0.0625 & 0.0002 & 0.0225 \\
STUCCO & 0.0141 & 0.0005 & 0.0034 \\
WOOD SIDING & 0.0327 & 0.0004 & 0.0046 \\
VINYL SIDING & 0.0295 & 0.0002 & 0.0098 \\
EIFS & 0.0129 & 0.0001 & 0.0058 \\
& & 0.0002 & 0.0237 \\
ASPHALT & 0.0207 & & 0.0015 \\
CLAY TILE & 0.0276 & 0.0005 & \\
\hline
\end{tabular}

After obtaining the normalized scores, which is a non-commensurate value, we calculate the weighted normalized decision matrix $(\mathrm{V})$ bye multiplying $\mathrm{R}$ by $\mathrm{W}$ as follows:

$\mathrm{V}=\mathrm{R} * \mathrm{~W}$

Table 4-5: Weighted Normalized Decision Matrix (V)

\begin{tabular}{|llll|}
\hline \multicolumn{1}{|c}{$\begin{array}{c}\text { MATERIAL/ } \\
\text { ASSEMBLY }\end{array}$} & \multicolumn{1}{c}{$\begin{array}{c}\text { GLOBAL } \\
\text { WARMING } \\
\text { POTENTIAL }\end{array}$} & HEALTH QUALITY & $\begin{array}{c}\text { FOSSIL FUEL } \\
\text { DEPLETION }\end{array}$ \\
STEEL & 0.0242 & 0 & 0.0017 \\
WOOD & 0.0112 & 0.0002 & 0.0008 \\
FIBERGLASS & 0.0028 & 0.0004 & 0.0006 \\
& & & 0.0225 \\
\hline BRICK \& MORTAR & 0.125 & 0.001 & \\
\hline
\end{tabular}




\begin{tabular}{|llll|}
\hline \multicolumn{1}{|c}{$\begin{array}{c}\text { MATERIAL/ } \\
\text { ASSEMBLY }\end{array}$} & \multicolumn{1}{c}{$\begin{array}{c}\text { GLOBAL } \\
\text { WARMING } \\
\text { POTENTIAL }\end{array}$} & HEALTH QUALITY & $\begin{array}{c}\text { FOSSIL FUEL } \\
\text { DEPLETION }\end{array}$ \\
STUCCO & 0.0282 & 0.0008 & 0.0034 \\
WOOD SIDING & 0.0654 & 0.0004 & 0.0046 \\
VINYL SIDING & 0.059 & 0.0002 & 0.0098 \\
EIFS & 0.0258 & 0.0004 & 0.0058 \\
ASPHALT & 0.0414 & & 0.0237 \\
CLAY TILE & 0.0552 & 0.001 & 0.0015 \\
\hline
\end{tabular}

The main task in this methodology is to determine the ideal and negative-ideal solution. This is calculated as:

$$
\begin{aligned}
& \text { Ideal solution set }(\mathrm{A}+) \quad=\{\mathrm{Min} \mathrm{V}\} \\
& =\{\text { Minimum value of each column of } \mathrm{V} \text { matrix }\} \\
& \text { Wall structural element } \quad=\left\{\begin{array}{lll}
0.0112 & 0 & 0.0008
\end{array}\right\}
\end{aligned}
$$

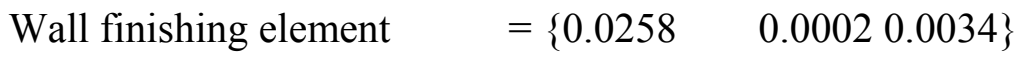

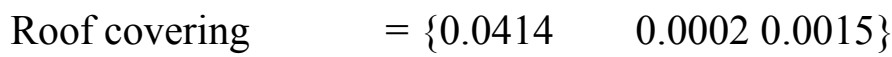

$$
\begin{aligned}
& \text { Negative-ideal solution set (A-) } \quad=\{\text { Max V }\} \\
& =\{\text { Maximum value of each column of } \mathrm{V} \text { matrix }\} \\
& \text { Wall structural element }=\left\{\begin{array}{lll}
0.0242 & 0.0002 & 0.0017
\end{array}\right\}
\end{aligned}
$$

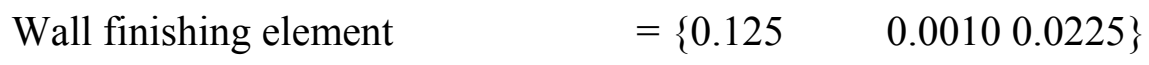

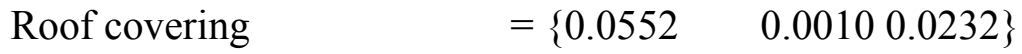

After having determined the ideal and negative-ideal solution sets, the separation measure, i.e. the distance of each alternative from two of the solution sets is to be calculated as follows:

$$
\mathrm{S}+=\sqrt{ }\left(\sum\left(\mathrm{V}_{\mathrm{ij}}-\mathrm{A}+_{\mathrm{j}}\right)^{2}\right.
$$


S- $=\sqrt{ }\left(\sum\left(V_{i j}-A_{-j}\right)^{2}\right.$

Where, " $\mathrm{i}$ " is the row and " $\mathrm{j}$ " is the column number.

That produces the following Matrices:

Table 4-6: Separation measures

\begin{tabular}{|lcc|}
\hline \multicolumn{1}{|c}{ MATERIAL/ ASSEMBLY } & S+ & S- \\
STEEL & 0.0130 & 0.0002 \\
WOOD & 0.0002 & 0.0130 \\
& & \\
BRICK \& MORTAR & 0.1010 & 0 \\
STUCCO & 0.0025 & 0.0986 \\
WOOD SIDING & 0.0396 & 0.0622 \\
VINYL SIDING & 0.0209 & 0.0672 \\
EIFS & 0.0024 & 0.1005 \\
& & 0.0138 \\
ASPHALT & 0.0222 & 0.0222 \\
CLAY TILE & 0.0138 & \\
\hline
\end{tabular}

With the separation distances in hand, now is the final step to calculate the relative closeness to the ideal solution by using the following equation:

$\mathrm{C}_{\mathrm{i}}=\left(\mathrm{S}-{ }_{\mathrm{i}}\right) /\left(\mathrm{S}+_{\mathrm{i}}+\mathrm{S}-{ }_{\mathrm{i}}\right)$

Where, " $\mathrm{i}$ " is the row number and $0<\mathrm{C}_{\mathrm{i}}<1$. By performing the above calculation, it produces the following ranking order of the materials assessed as shown in table 4-7. Table 4-7: Relative ranking of alternatives

\begin{tabular}{|c|c|}
\hline MATERIAL/ ASSEMBLY & $\bar{C}$ \\
\hline STEEL & 0.0151 \\
\hline WOOD & 0.9849 \\
\hline BRICK \& MORTAR & 0 \\
\hline STUCCO & 0.9753 \\
\hline
\end{tabular}




\begin{tabular}{|lc|}
\hline \multicolumn{1}{|c|}{ MATERIAL/ ASSEMBLY } & C \\
WOOD SIDING & 0.6110 \\
VINYL SIDING & 0.7627 \\
EIFS & 0.9766 \\
\end{tabular}

Finally, after all calculation, alternatives Wood and EIFS are preferred for constructing wall structural and wall finishing element, as it possesses the highest value.

\subsection{Assessing Environmental impact of Component Assemblies}

A component assembly, as mentioned earlier in this study, is defined as the way a building element is constructed. Unlike materials, a component assembly is not a single element, but is the combination of different materials used in its construction. So, the impact of an assembly is the addition of the impacts of each material used in its construction. In order to assess the impacts of component assemblies, the present study draws required information from Athena's Eco Calculator. Athena's Eco calculator, as elaborated in Chapter 2 of this study, calculates the impacts of the pre-defined component assemblies. Eco calculator assesses two kinds of wall system and one type of roof system. The types of wall system used are the cavity wall and the built-up wall and the roof system studied is built-up as well. Possible combinations of exterior wall assemblies, for which Athena calculates the impacts, are given below in table 4-8

Table 4-8: EXTERIOR WALL ASSEMBLY COMBINATIONS

\begin{tabular}{|c|c|c|c|}
\hline $\begin{array}{l}\text { FRAMING } \\
\text { MATERIALS }\end{array}$ & $\begin{array}{l}\text { SHEATHING } \\
\text { AND } \\
\text { INSULATION }\end{array}$ & $\begin{array}{l}\text { FINISHING } \\
\text { MATERIALS }\end{array}$ & TYPE OF WALL \\
\hline \multirow[t]{3}{*}{ WOOD STUDS } & \multirow{3}{*}{$\begin{array}{l}\text { ORIENTAL } \\
\text { STRAND BOARD, } \\
\text { R5 XPS } \\
\text { CONTINUOS \& } \\
\text { R13 CAVITY } \\
\text { INSULATION, } \\
\text { WEATHER }\end{array}$} & CLAY BRICK & CAVITY WALL \\
\hline & & STUCCO & \multirow[t]{2}{*}{ BUILT UP WALL } \\
\hline & & VINYL SIDING & \\
\hline
\end{tabular}




\begin{tabular}{|l|l|l|l|}
\hline STEEL STUDS & RESISTANT & CEDAR BEVEL & \\
& BARRIER, \\
& $1 / 2$ ' GYPSUM & SIDING & \\
\cline { 2 - 3 } & BOARD, & EIFS & \\
2 COATS LATEX & & \\
PAINT & & \\
& & & \\
\hline
\end{tabular}

Table 4-8 Continued

In this regard, another Table 4-9 shows the impacts of each type of exterior wall component assembly extracted from the Athena's Eco calculator database based on $1 \mathrm{Sq}$.

Ft area of exterior wall.

Table 4-9: IMPACTS OF WALL ASSEMBLIES PER SFT

\begin{tabular}{|c|c|c|c|c|c|}
\hline $\begin{array}{l}\text { WALL } \\
\text { FRAME }\end{array}$ & INSULATION & $\begin{array}{c}\text { FINISH } \\
\text { MATERIAL }\end{array}$ & $\begin{array}{c}\text { FOSSIL } \\
\text { FUEL } \\
\text { DEPLETION }\end{array}$ & $\begin{array}{c}\text { GLOBAL } \\
\text { WARMING } \\
\text { POTENTIAL }\end{array}$ & $\begin{array}{l}\text { HEALTH } \\
\text { QUALITY }\end{array}$ \\
\hline & & & (MJ) & $\left.(\mathrm{kg} \mathrm{CO})_{2}\right)$ & $(\mathrm{mD})$ \\
\hline \multirow[t]{5}{*}{$\begin{array}{l}\text { WOOD } \\
\text { STUDS }\end{array}$} & \multirow[t]{5}{*}{$\begin{array}{lll}\text { R5 } & \text { XPS } \quad \& \\
\text { R13 } & & \end{array}$} & $\begin{array}{l}\text { CLAY } \\
\text { BRICK + } \\
\text { AIR SPACE }\end{array}$ & 119.81 & 8.11 & 23.32 \\
\hline & & STUCCO & 87.99 & 5.24 & 18.58 \\
\hline & & $\begin{array}{l}\text { VINYL } \\
\text { SIDING }\end{array}$ & 103.80 & 5.66 & 20.74 \\
\hline & & $\begin{array}{l}\text { CEDAR } \\
\text { SIDING }\end{array}$ & 87.96 & 5.18 & 18.27 \\
\hline & & EIFS & 115.92 & 5.95 & 31.07 \\
\hline \multirow[t]{5}{*}{$\begin{array}{l}\text { STEEL } \\
\text { STUDS }\end{array}$} & \multirow[t]{5}{*}{$\begin{array}{l}\text { R5 XPS \& } \\
\text { R13 }\end{array}$} & $\begin{array}{l}\text { CLAY } \\
\text { BRICK }+ \\
\text { AIR SPACE }\end{array}$ & 143.76 & 9.73 & 25.33 \\
\hline & & STUCCO & 111.95 & 6.85 & 20.58 \\
\hline & & $\begin{array}{l}\text { VINYL } \\
\text { SIDING }\end{array}$ & 127.75 & 7.28 & 22.75 \\
\hline & & $\begin{array}{l}\text { CEDAR } \\
\text { SIDING }\end{array}$ & 111.9 & 6.79 & 20.27 \\
\hline & & EIFS & 132.50 & 7.18 & 32.56 \\
\hline
\end{tabular}

With the performance scores of each assembly type, the present study is not aiming at normalizing and ranking the different combinations, like the calculations 
performed on material alternatives using TOPSIS. This study attempts to analyze the influence of the type of wall assembly irrespective of the materials used. In the above table 4-9, there are typically two kinds of wall assembly: cavity wall (with clay brick as facing material) and built-up wall (with 4 alternatives for facing material). To analyze, the differences between cavity wall and built up wall under each impact category is calculated. This is compared against the difference between two same materials that are used in the cavity and built up wall assembly respectively. Care is taken that the materials, both individually and in the assembly, are of the same dimensions and specifications. For easy understanding, each material alternative is abbreviated in the calculations as follows:

Clay brick: B Wood stud: W

Stucco: S Steel stud: T

Vinyl Siding: V Fiberglass: F

Cedar Siding: C Air Space: A

EIFS: E Common components between two assemblies: Y Fossil fuel depletion, compared between only materials and materials used in wall assembly (for example clay brick and cedar siding) can be shown by the following calculation:

$\begin{array}{lll}\mathrm{W}+\mathrm{Y}+(\mathrm{B}+\mathrm{A}) & =119.81 & \text { - eq. } 1 \\ \mathrm{~W}+\mathrm{Y}+\mathrm{C} & =87.96 & \text { - eq. } 2\end{array}$

Difference between eq. $1 \& 2$ gives $\quad \underline{(\mathrm{B}+\mathrm{A})-\mathrm{C}=31.85 \quad-\text { eq. } 3}$

$\mathrm{B}=6.37 \quad$ - eq. 4

$\mathrm{C}=1.65 \quad-$ eq. 5

Difference between eq. $4 \& 5$ gives $\underline{B}-\mathrm{C}=4.72 \quad$ - eq. 6 
When observed, it can be found that A is responsible for a difference about 27.13 MJ of fossil fuel depletion between two equations 3 and 6 .

Similarly, after approximate calculations for the rest of the impact categories and between other material alternatives, the following three charts were developed which showed the difference between materials and material used in assemblies:

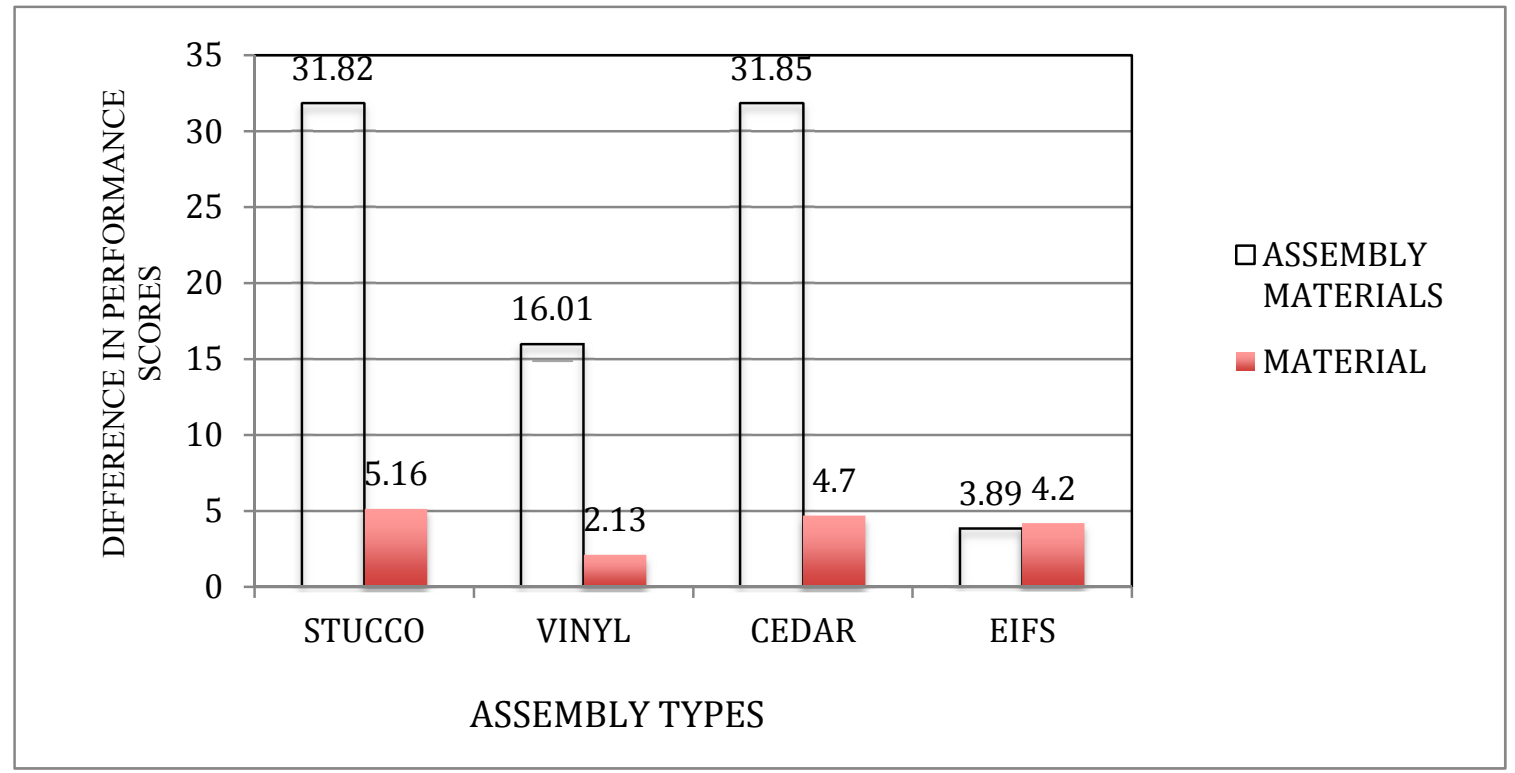

Figure 4-2: FOSSIL FUEL DEPLETION COMPARISON (MEASURED IN MJ)

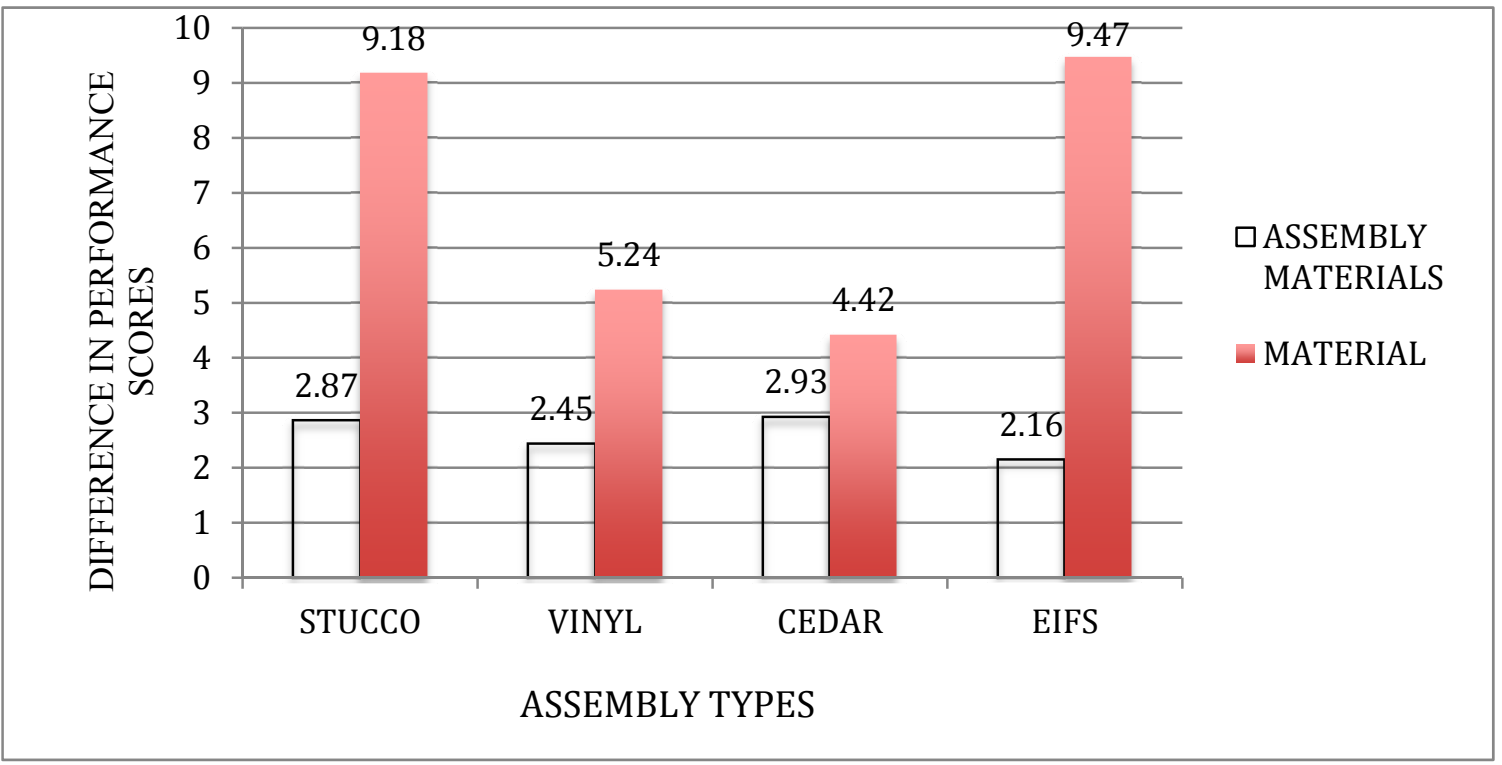

Figure 4-3: GLOBAL WARMING POTENTIAL COMPARISON (MEASURED IN kg of CO ${ }_{2}$ ) 


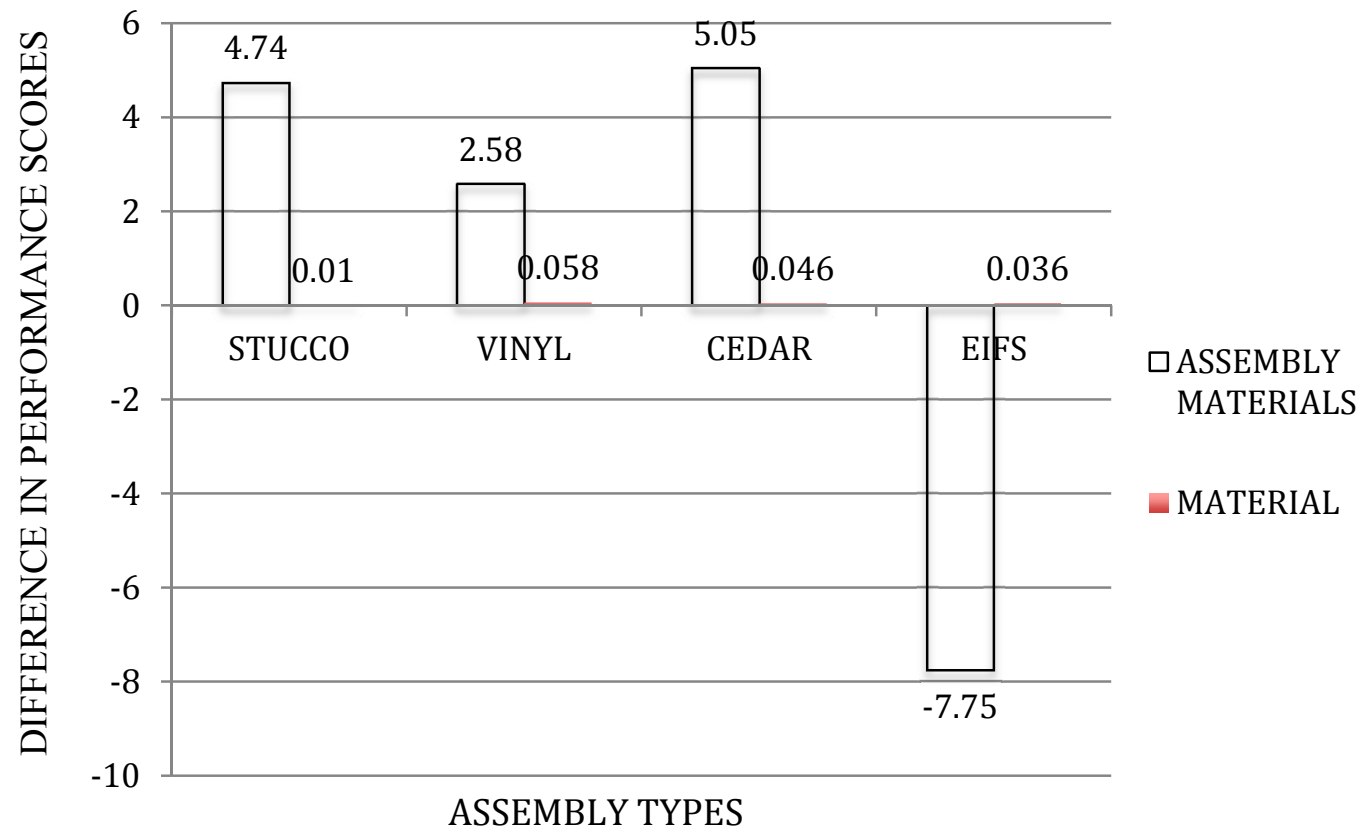

Figure 4-4: HEALTH QUALITY INDEX COMPARISON (MEASURED IN microDALY)

\subsection{Summary}

It is a known fact that the only difference between two types of wall assemblies built with the same materials is the air space that is present in the cavity wall and which is absent in the built-up wall. With this, it can be interpreted from the calculations shown in the previous section that the difference between performance of one material from another material exclusively and the difference between performance of the same materials used in the assembly highly varies. Most of the portion of this variation is highly associated with the presence/ absence of the air space in the wall assemblies. A conclusion that can be drawn from this is that it is not only material used in the construction that is responsible for the impacts on environments but also the way the component is constructed is the factor that highly influences the performance from an environmental perspective. 


\section{CHAPTER 5: EVALUATING ENVIRONMENTAL AND COST IMPACTS}

\subsection{Introduction}

With the costs and environmental impacts assessed for the material alternatives and the assemblies, for an effective decision-making there is a much-needed support in terms of evaluation. Any tool that is used as a part of a formal or informal decisionmaking process can be called as Decision Support Tool (DST) (Kapelan et al. 2005).

There are numerous DSTs available in the construction industries that aid the designers and planners in incorporating new green building requirements but it the application of these tools that overwhelm the designers and planners when it comes to decision-making (Carmody et al. 2000). Decision Support Tools in green buildings context are of many types. CMHC (2004) categorizes them into two ways: interactive software and passive tools. The difference between these two types is the way the user is required to input the data and the extent to manipulate information. CMHC further divides the two into the following categories:

Table 5-1: Types of Decision Support Tools

\begin{tabular}{|l|l|}
\hline \multicolumn{1}{|c|}{ INTERACTIVE } & \multicolumn{1}{c|}{ PASSIVE } \\
\hline $\begin{array}{l}\text { Life Cycle Assessment Tools for Buildings } \\
\text { and Building Stocks }\end{array}$ & $\begin{array}{l}\text { Environmental Assessment Frameworks } \\
\text { and Rating Systems }\end{array}$ \\
\hline Energy and Ventilation Modeling Software & $\begin{array}{l}\text { Environmental Guidelines or checklists for } \\
\text { Design and Management of Buildings }\end{array}$ \\
\hline & $\begin{array}{l}\text { Environmental Products Declarations, } \\
\text { Catalogues, Reference Information, } \\
\text { Certifications and Labels. }\end{array}$ \\
\hline
\end{tabular}


In addition to the above classification, the other types of tools considered are web sites, databases, directories, standards and any other relevant resources that support the design process.

Tools are developed to satisfy various tasks with various user requirements, time and resource constraints, objectives and goals etc.

The present study aims at formulating a passive type of Decision Support Tool that rates the alternatives based on its performance obtained by a life cycle assessment. The following sections of this chapter elaborate on the evaluation of impacts.

\subsection{Analyzing combined impacts of materials and component assemblies}

After analyzing impacts associated with cavity and built up wall and concluding that the type of wall plays a significant role in creating impacts on environment, this section attempts to evaluate the performances of different combinations of materials and wall assemblies. All the possible combinations with the materials and type of wall assembly are given below:

TABLE 5-2 MATERIALS AND ASSEMBLY COMBINATIONS

\begin{tabular}{|l|c|c|c|}
\multicolumn{1}{|c|}{$\begin{array}{c}\text { FRAMING } \\
\text { MATERIALS }\end{array}$} & $\begin{array}{c}\text { SHEATHING } \\
\text { AND } \\
\text { INSULATION }\end{array}$ & $\begin{array}{c}\text { FINISHING } \\
\text { MATERIALS }\end{array}$ & TYPE OF WALL \\
\hline 1. WOOD STUDS & OSB/ R5 + R13 & CLAY BRICK & CAVITY \\
\hline 2. WOOD STUDS & OSB/ R5 + R13 & STUCCO & CAVITY \\
\hline 3. WOOD STUDS & OSB/ R5 + R13 & VINYL SIDING & CAVITY \\
\hline 4. WOOD STUDS & OSB/ R5 + R13 & CEDAR SIDING & CAVITY \\
\hline 5. WOOD STUDS & OSB/ R5 + R13 & EIFS & CAVITY \\
\hline 6. WOOD STUDS & OSB/ R5 + R13 & CLAY BRICK & BUILT-UP \\
\hline 7. WOOD STUDS & OSB/ R5 + R13 & STUCCO & BUILT-UP \\
\hline 8. WOOD STUDS & OSB/ R5 + R13 & VINYL SIDING & BUILT-UP \\
\hline 9. WOOD STUDS & OSB/ R5 + R13 & CEDAR SIDING & BUILT-UP \\
\hline 10. WOOD STUDS & OSB/ R5 + R13 & EIFS & BUILT-UP \\
\hline & & & \\
\hline 11. STEEL STUDS & OSB/ R5 + R13 & CLAY BRICK & CAVITY \\
\hline 12. STEEL STUDS & OSB/ R5 + R13 & STUCCO & CAVITY \\
\hline
\end{tabular}




\begin{tabular}{|l|c|c|c|}
\hline $\begin{array}{c}\text { FRAMING } \\
\text { MATERIALS }\end{array}$ & $\begin{array}{c}\text { SHEATHING } \\
\text { AND } \\
\text { INSULATION }\end{array}$ & $\begin{array}{c}\text { FINISHING } \\
\text { MATERIALS }\end{array}$ & TYPE OF WALL \\
\hline 13. STEEL STUDS & OSB/ R5 + R13 & VINYL SIDING & CAVITY \\
\hline 14. STEEL STUDS & OSB/ R5 + R13 & CEDAR SIDING & CAVITY \\
\hline 15. STEEL STUDS & OSB/ R5 + R13 & EIFS & CAVITY \\
\hline 16. STEEL STUDS & OSB/ R5 + R13 & CLAY BRICK & BUILT-UP \\
\hline 17. STEEL STUDS & OSB/ R5 + R13 & STUCCO & BUILT-UP \\
\hline 18. STEEL STUDS & OSB/ R5 + R13 & VINYL SIDING & BUILT-UP \\
\hline 19. STEEL STUDS & OSB/ R5 + R13 & CEDAR SIDING & BUILT-UP \\
\hline 20. STEEL STUDS & OSB/ R5 + R13 & EIFS & BUILT-UP \\
\hline & & & \\
\hline
\end{tabular}

From section 4.3 the data associated with the environmental impacts is extracted and with an assumption that the presence/ absence of the air space responsible for the difference of impacts on the two types of wall, the performances are re-calculated as shown in table 5-3.

TABLE 5-3 RE-CALCULATION OF PERFORMANCE OF ASSEMBLIES

\begin{tabular}{|c|c|c|c|}
\hline WALL TYPE & $\begin{array}{l}\text { FOSSIL FUEL } \\
\text { DEPLETION } \\
\text { (MJ) }\end{array}$ & $\begin{array}{c}\text { GLOBAL } \\
\text { WARMING } \\
\text { POTENTIAL } \\
\left(\mathrm{kg} \text { of } \mathrm{CO}_{2}\right)\end{array}$ & $\begin{array}{c}\text { HEALTH } \\
\text { QUALITY INDEX } \\
\text { (microDALY) }\end{array}$ \\
\hline BRICK (W. CAVITY) & 119.81 & 8.11 & 23.32 \\
\hline STUCCO (W. CAVITY) & 111.89 & -0.46 & 22.78 \\
\hline VINYL (W. CAVITY) & 116.3 & 3.16 & 23.04 \\
\hline CEDAR (W. CAVITY) & 112.36 & 3.88 & 22.77 \\
\hline EIFS (W. CAVITY) & 115.64 & -0.55 & 24.07 \\
\hline BRICK (S. CAVITY) & 143.76 & 9.73 & 25.33 \\
\hline STUCCO (S. CAVITY) & 135.93 & 1.18 & 24.84 \\
\hline VINYL (S. CAVITY) & 140.06 & 4.78 & 25.01 \\
\hline CEDAR (S. CAVITY) & 136.32 & 5.46 & 24.78 \\
\hline EIFS (S. CAVITY) & 138.85 & 0.95 & 39.1 \\
\hline BRICK (W. BUILT UP) & 104.68 & 4.11 & 22.32 \\
\hline STUCCO (W. BUILT UP) & 87.99 & 5.24 & 18.58 \\
\hline VINYL (W. BUILT UP) & 103.80 & 5.66 & 20.74 \\
\hline CEDAR (W. BUILT UP) & 87.96 & 5.18 & 18.27 \\
\hline EIFS (W. BUILT UP) & 115.92 & 5.95 & 31.07 \\
\hline BRICK (S. BUILT UP) & 127 & 5.83 & 20.94 \\
\hline STUCCO (S. BUILT UP) & 111.95 & 6.85 & 20.58 \\
\hline VINYL (S. BUILT UP) & 127.75 & 7.28 & 22.75 \\
\hline CEDAR (S. BUILT UP) & 111.9 & 6.79 & 20.27 \\
\hline EIFS (S. BUILT UP) & 132.50 & 7.18 & 32.56 \\
\hline
\end{tabular}


After performing the calculations for all possible assemblies, for the three impact categories, the interpretation can be done as follows:

- Except in few combinations, there is a huge influence of the air space (1" thick in these wall assemblies) on the performance.

- The performance scores mostly fall in the same range for almost all the material and assembly combinations.

- The negative scores indicate that the performance of the assembly is reversed in that impact category (in this case, reducing GWP is considered to be positive trait) With the above implications, of obtaining nearly equivalent scores, the cost impacts of the two types of wall assemblies are analyzed.

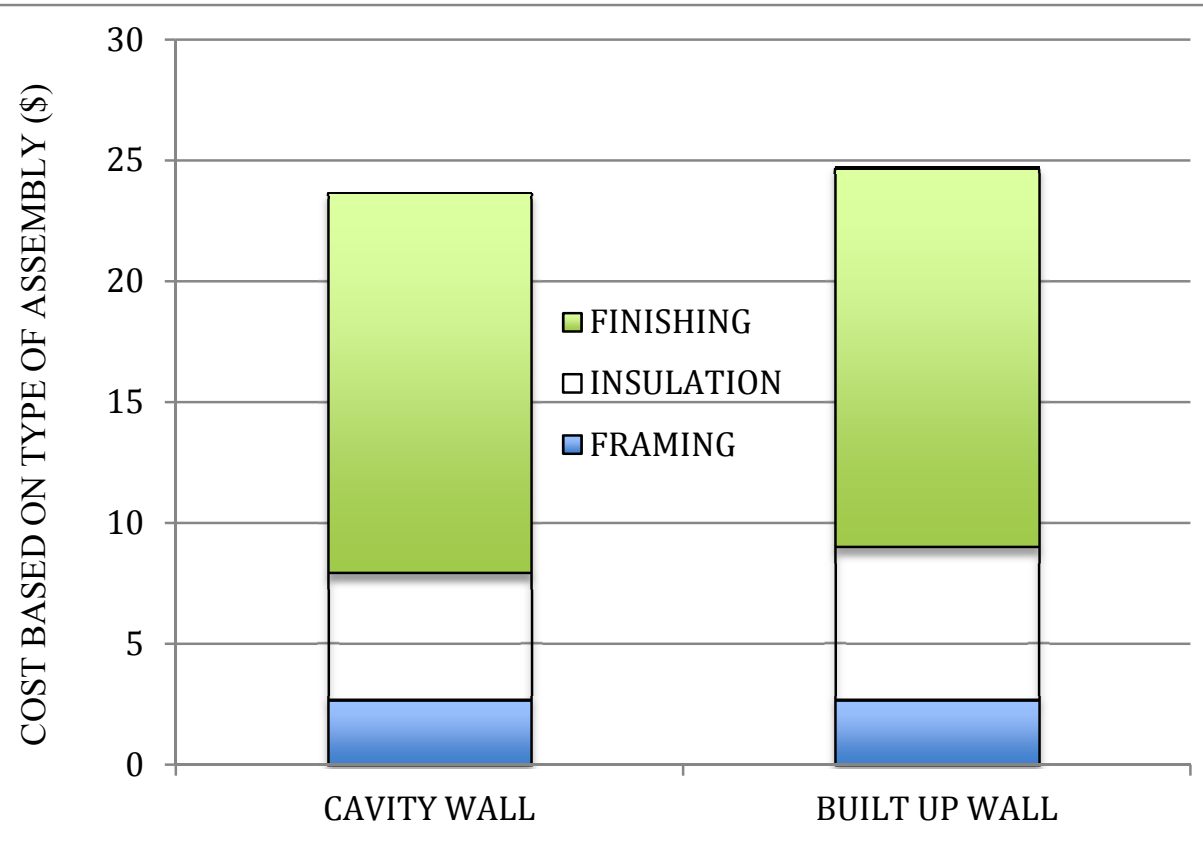

FIGURE 5-1: COST DIFFERENCE BETWEEN CAVITY AND BUILTUP WALL

The difference in the two types of the assembly is associated with the type of minimum treatment required for the cavity insulation in cavity walls and insulation between face and back up layer of built up wall. The reflected costs are calculated per square feet. 


\subsection{Case study}

In order to compare the impacts of various combinations of materials and assemblies on a larger spatial scale, a case study was incorporated in this study, The building selected had an area $1224 \mathrm{Sq}$. Ft of the exterior walls (extracted from the architectural plans).

The north, east and south walls were considered to have $40 \%$ of the area for the openings. In this case, the performance scores with the total area of the exterior walls (Whole Building) are calculated and the following numbers are obtained:

TABLE 5-4: ENVIRONMENTAL IMPACTS OF BUILDING'S EXTERIOR WALL

\begin{tabular}{|r|r|r|r|}
\multicolumn{1}{|c|}{ WALL TYPE } & $\begin{array}{c}\text { FOSSIL FUEL } \\
\text { DEPLETION } \\
\text { (MJ) }\end{array}$ & $\begin{array}{c}\text { GLOBAL } \\
\text { WARMING } \\
\text { POTENTIAL } \\
\text { (kg of CO }\end{array}$ & $\begin{array}{r}\text { HEALTH } \\
\text { QUALITY } \\
\text { INDEX } \\
\text { (microDALY) }\end{array}$ \\
\hline BRICK (W. CAVITY) & 146647.44 & 9926.64 & 28543.68 \\
\hline STUCCO (W. CAVITY) & 136953.36 & -563.04 & 27882.72 \\
\hline VINYL (W. CAVITY) & 142351.2 & 3867.84 & 28200.96 \\
\hline CEDAR (W. CAVITY) & 137528.64 & 4749.12 & 27870.48 \\
\hline EIFS (W. CAVITY) & 141543.36 & -673.2 & 29461.68 \\
\hline BRICK (S. CAVITY) & 175962.24 & 11909.52 & 31003.92 \\
\hline STUCCO (S. CAVITY) & 166378.32 & 1444.32 & 30404.16 \\
\hline VINYL (S. CAVITY) & 171433.44 & 5850.72 & 30612.24 \\
\hline CEDAR (S. CAVITY) & 166855.68 & 6683.04 & 30330.72 \\
\hline EIFS (S. CAVITY) & 169952.4 & 1162.8 & 47858.4 \\
\hline BRICK (W. BUILT UP) & 128128.32 & 5030.64 & 27319.68 \\
\hline STUCCO (W. BUILT UP) & 107699.76 & 6413.76 & 22741.92 \\
\hline VINYL (W. BUILT UP) & 127051.2 & 6927.84 & 25385.76 \\
\hline CEDAR (W. BUILT UP) & 107663.04 & 6340.32 & 22362.48 \\
\hline EIFS (W. BUILT UP) & 141886.08 & 7282.8 & 38029.68 \\
\hline BRICK (S. BUILT UP) & 155448 & 7135.92 & 25630.56 \\
\hline STUCCO (S. BUILT UP) & 137026.8 & 8384.4 & 25189.92 \\
\hline VINYL (S. BUILT UP) & 156366 & 8910.72 & 27846 \\
\hline CEDAR (S. BUILT UP) & 136965.6 & 8310.96 & 24810.48 \\
\hline EIFS (S. BUILT UP) & 162180 & 8788.32 & 39853.44 \\
\hline
\end{tabular}


FIGURE 5-2: FLOOR PLAN OF A BUILDING

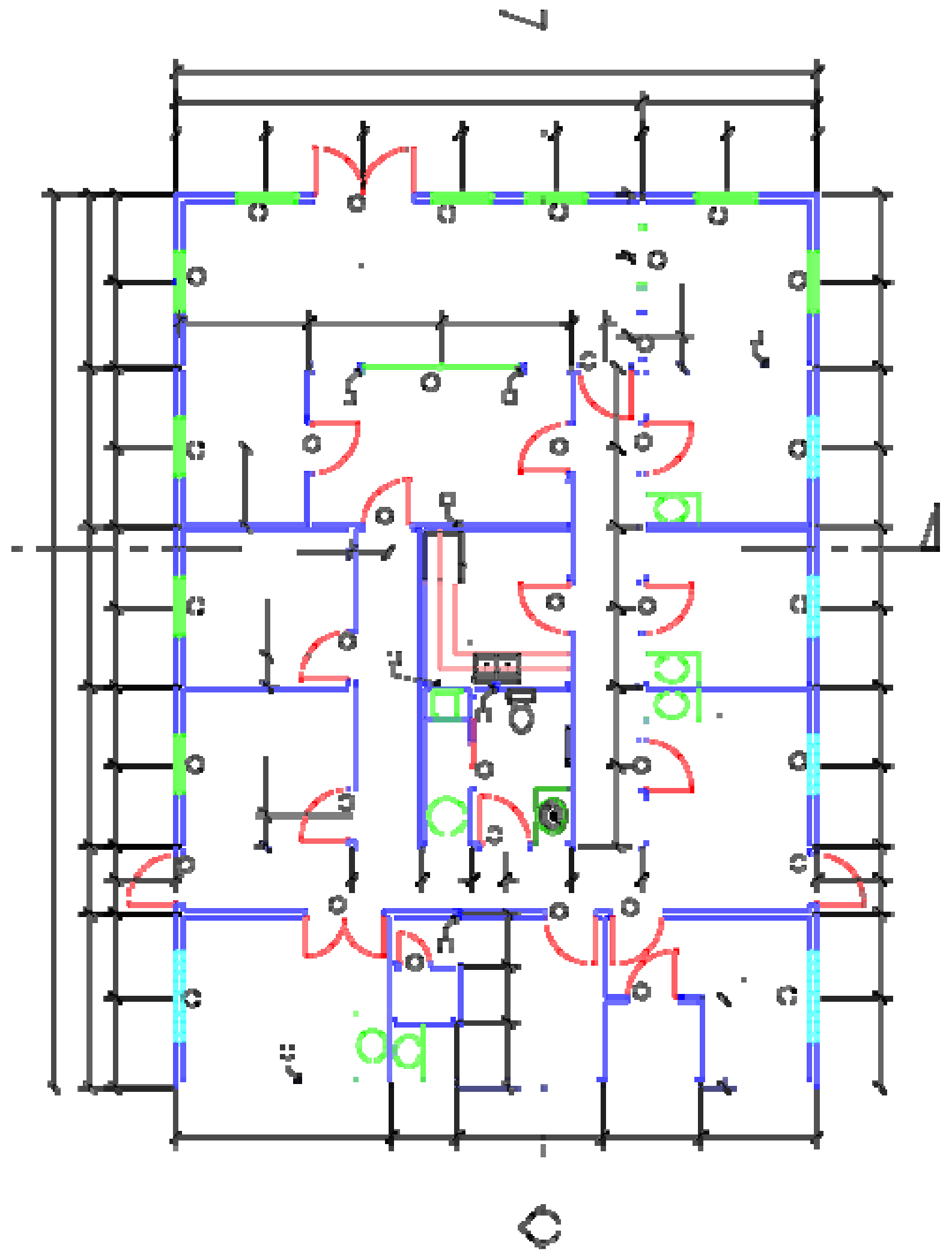




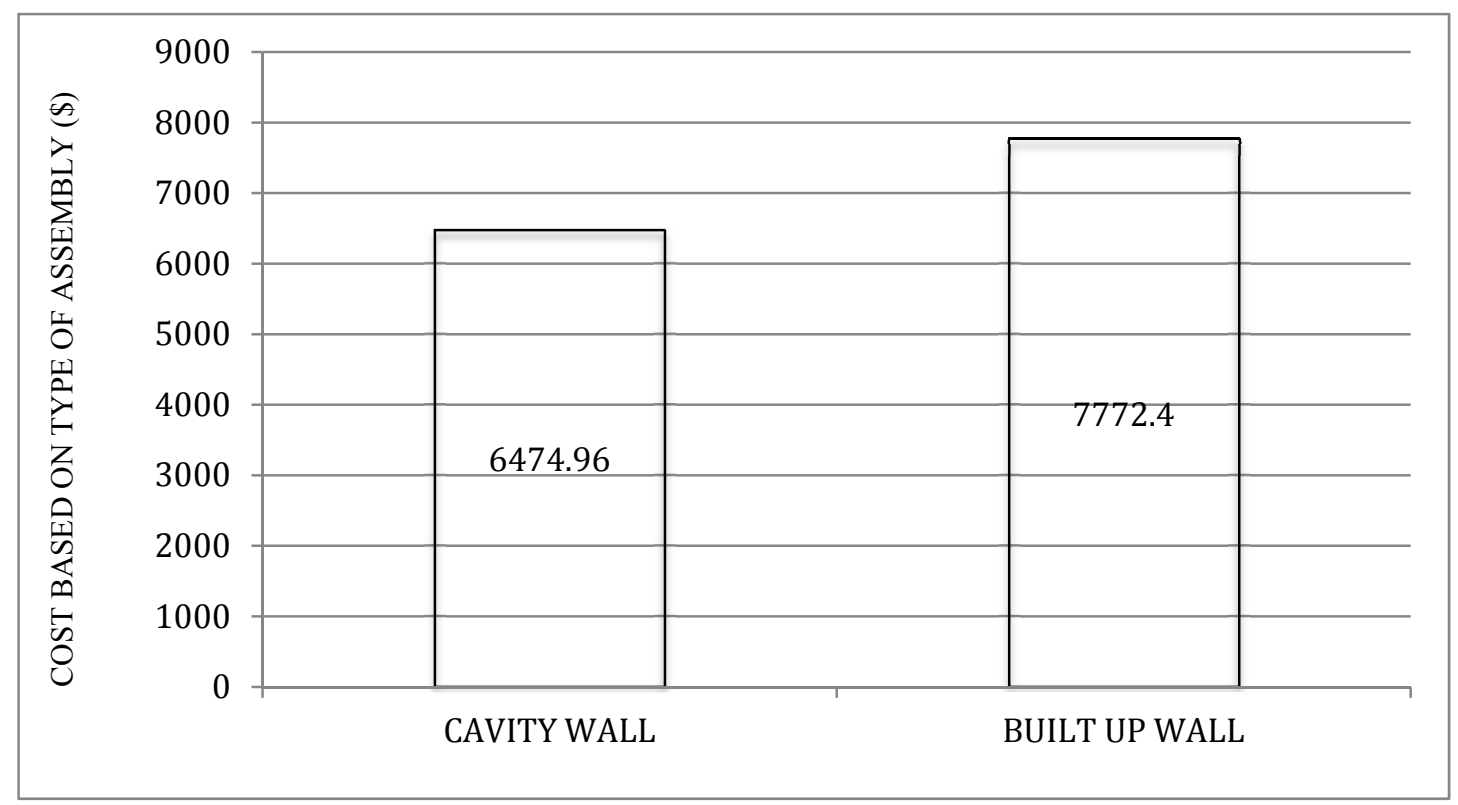

FIGURE 5-3: COST IMPACTS OF BUILDING'S EXTERIOR WALL (\$)

\subsection{Results}

After clearly identifying the performance of various materials and component assemblies, decision-makers are more knowledgeable in selecting weights that reflect their personal reliability on each analysis. In this case study, giving no weights, to evaluate the total performance of both the component assemblies, the analysis was performed. This is done to examine the effects on the scores when compared on a larger spatial scale rather than comparing at unit Sq Ft level.

The results demonstrate that based on importance weights, which a decisionmaker can create based on his requirements, a built up wall cost $\$ 1297.44 .00$ more than a cavity wall. To a more extensive indication of the performance of these assemblies, it can be stated that the environmental performance difference between the two assemblies (both on larger scale and unit Sq. Ft level) did not show a figure of major concern. 


\subsection{Evaluation Tool}

As calculated in the previous section, the aggregate environmental impact and first costs are summarized in the following table 5-5.

Table 5-5: Environmental scores and cost of assemblies

\begin{tabular}{|c|c|c|c|}
\hline ASSEMBLY TYPE & ENV. SCORE & $\operatorname{COST}(\$)($ per SFT $)$ & $\begin{array}{c}\text { ABBREVIATION } \\
\text { USED IN THE TOOL }\end{array}$ \\
\hline EIFS (S. CAVITY) & 0.050679311 & 18.66 & EIFS (S.C) \\
\hline EIFS (S. BUILT UP) & 0.278246478 & 19.72 & EIFS (S.B) \\
\hline EIFS (W. BUILT UP) & 0.425700493 & 18.27 & EIFS (W.B) \\
\hline BRICK (S. CAVITY) & 0.451424035 & 24.19 & B (S.C) \\
\hline VINYL (S. CAVITY) & 0.473818141 & 10.46 & V (S.C) \\
\hline CEDAR (S. CAVITY) & 0.496403288 & 12.39 & $\mathrm{C}(\mathrm{S} . \mathrm{C})$ \\
\hline STUCCO (S. CAVITY) & 0.496801551 & 15.46 & S (S.C) \\
\hline VINYL (S. BUILT UP) & 0.590997157 & 11.52 & V (S.B) \\
\hline BRICK (W. CAVITY) & 0.630027539 & 22.74 & B (W.C) \\
\hline BRICK (S. BUILT UP) & 0.631082327 & 25.25 & B (S.B) \\
\hline EIFS (W. CAVITY) & 0.639608399 & 17.21 & EIFS (W.C) \\
\hline VINYL (W. CAVITY) & 0.661514286 & 9.01 & V (W.C) \\
\hline CEDAR (W. CAVITY) & 0.696850728 & 10.94 & \\
\hline STUCCO (W. CAVITY) & 0.70006642 & 14.01 & \\
\hline STUCCO (S. BUILT UP) & 0.747088765 & 16.52 & \\
\hline CEDAR (S. BUILT UP) & 0.752715072 & 13.45 & \\
\hline BRICK (W. BUILT UP) & 0.7653771 & 23.8 & \\
\hline VINYL (W. BUILT UP) & 0.811216735 & 10.07 & \\
\hline STUCCO (W. BUILT UP) & 0.987990614 & 15.07 & \\
\hline CEDAR (W. BUILT UP) & 0.999833146 & 12 & \\
\hline
\end{tabular}


The table shows all possible combinations of assemblies that are arranged in the ascending order based on their environmental scores. In order to formulate a tool, all the assembly types that fall below the least possible cost and which has high negative environmental impacts are disregarded. Hence, the tool developed shows the possible solutions for the first 12 selected assembly types.

The following figure 5-4 shows the best possible solutions from the tool.

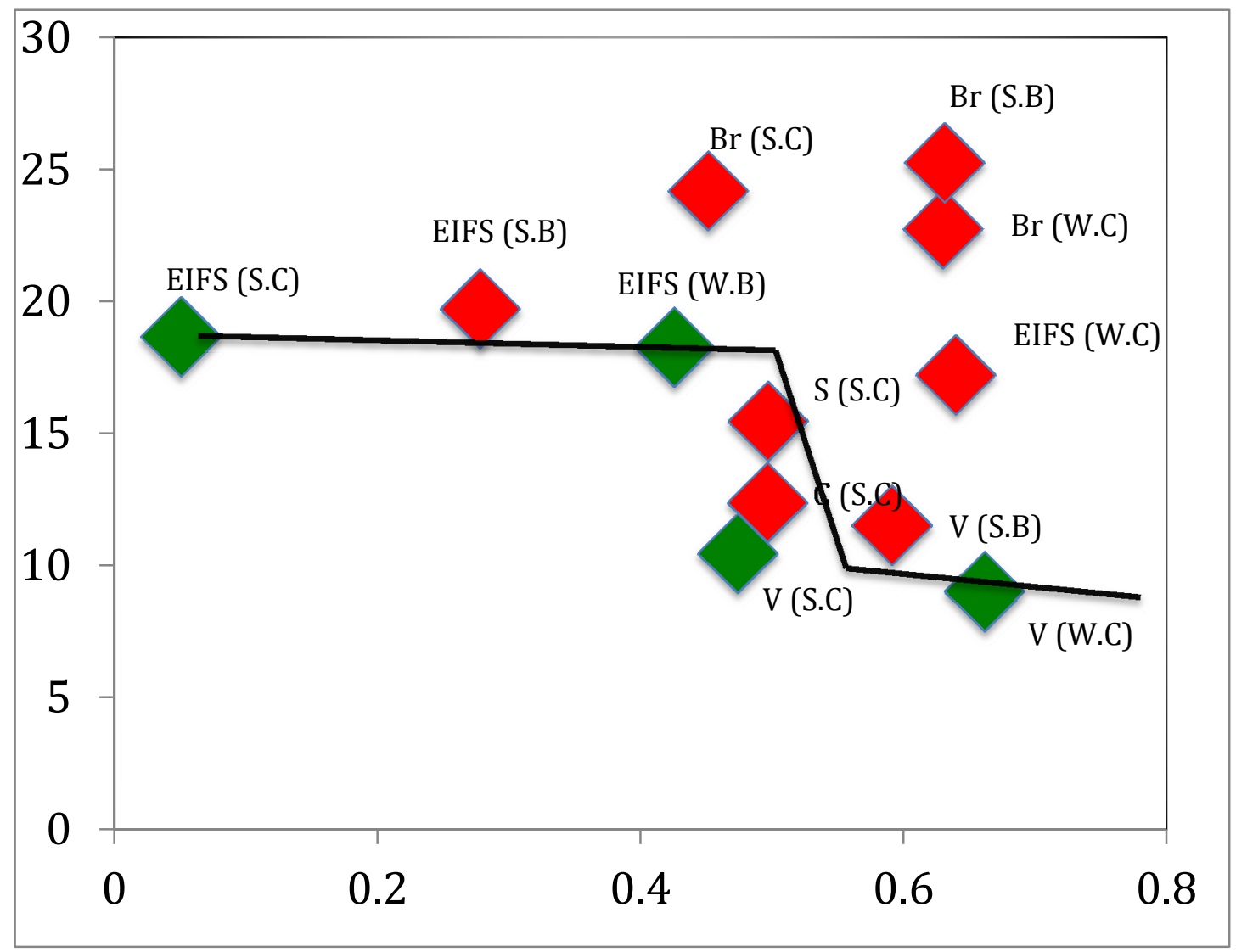

Figure 5-4: Decision-making tool for the given alternatives

From the above tool we understand that the out of 12 possible assemblies, 4 of them can be the best solutions based on the decision-makers criteria. For example, if the decision-maker's criteria were selecting an assembly that has least cost, then V (W.C) would be the solution. On the other hand, if the criteria were selecting an assembly with 
least negative environmental impact, then EIFS (S.C) would be the solution. All the assemblies that fall out of the ideal possible solution line may not be the solution for environmental and cost criteria but they may be the best possible solution for a decisionmaker with different criteria such as aesthetics etc.

\subsection{Summary}

To add to all the previous researches, Hubermann and Pearlmutter (2008) emphasizes the importance of expressing the results of impacts in a functional unit that represents building elements (i.e. $\mathrm{ft}^{2}$ of wall]) or the entire house (i.e. [ $\mathrm{ft}^{2}$ of floor area]) rather than comparing scores of the impact of building materials. This is because materials vary largely in terms of densities and contents of concentration of various composed materials. To the matter of fact, for comparison purpose, it is much easier to compare the environmental performances of building elements instead of separate materials that, alone, do not represent the performance of a building's function. 


\section{CHAPTER 6: CONCLUSIONS}

The objective of the present study is to support decision-makers in selecting building materials and type of component assembly that are environmentally and economically balanced through a proposed qualitative evaluation system. The case study results that had high variability in performance scores was the motivation for the system. A case study was developed to test the evaluation system. The results disprove conventional perceptions, including the intuition that natural materials are more environmentally preferable compared to the latest developed composite materials. Such results further reinforce the significance in taking a multi-attribute approach to assessing a building product's sustainable and financial performance. The case study exposes the way in which the proposed system transparently demonstrates the implications of each analysis. It also proved the practicality of using the system, as it gives an insight of combining environmental and cost performance into an integrated performance value that is easily interpreted. Ultimately, the system exposes the true environmental and economic sustainability of building materials with the help of tools readily available in the market. The proposed decision support system is a basis for developing a comprehensive building material assessment tool with the combination of type of component assembly that can be potentially used for estimating the impacts it has on environment and economy. 


\section{CHAPTER 7: RECOMMENDATION FOR FURTHER RESEARCH}

Advances in research and development are perceived to promote a more reliable and popularized use of LCA. In the meantime, it is recommended that projects begin incorporating the whole building system, using LCA in order to begin setting benchmarks for the industry. This would transform the way the industry performs environmental assessment on whole-building assemblies and materials and perhaps enhance research in more simplified tools and methods to conduct LCA.

In addition to the above recommendation, another recommended follow-up to this study is to perform a comprehensive cost study on common building elements. By studying the cost variability within those elements, other factors that account for variation can also be accounted. The cost variability problem can also be investigated by studying the role of economical databases in construction, such as RS Means, etc. Lastly, in order to focus on a more integrated approach, it is necessary to account for the operational and maintenance costs of selecting specific materials and component assemblies.

This study provides a framework as a base for further development. It is necessary to investigate the environmental and cost effects and variability of several building materials and ultimately complete a similar study on an entire building to validate the proposed evaluation system. Such comprehensive study can result in more accurate conclusions on the environmental and cost results of selecting a suitable material for a particular component assembly.

Furthermore, an integrated study can identify the opportunities and challenges of using LCA methodology and costing analysis when evaluating the performance of an entire building. Finally, a proper methodology to calculate the overall performance 
(environmental and cost), which can consider a weighted system and provide accurate results is a domain further studies can be done extensively. 


\section{LIST OF REFERENCES}

Abeysundara, U. G. Y., Babel, S., and Gheewala, S. (2009). "A matrix in life-cycle perspective for selecting sustainable materials for buildings in Sri Lanka". Building and Environment, 44(5), 997-1004.

Adalberth, K. (1997). Energy use during the life-cycle of single-unit dwellings: examples. Building and Environment, 32, 321-329.

Asif, M., Muneer, T., Kelley, R. (2007). Life cycle assessment: A case study of a dwelling home in Scotland. Building and Environment, 42, 1391-1394.

ATHENA Institute (2011). The EcoCalculator for Buildings. Retrieved, March 25, 2011, from http://athenasmi.org/tools/ecoCalculator/index.html

ATHENA Institute (2011). The Impact Estimator for Buildings. Retrieved from http://athenasmi.org/tools/impactEstimator/

Bare, J.C. (2002). "Developing a Consistent Decision-Making Framework by Using the U.S. EPA's TRACI”. AICHE. Retrieved from http://www.epa.gov/

Bayer, C., Gamble, M., Gentry, R., and Joshi, S. (2010). "AIA Guide to Building Life Cycle Assessment in Practice". The American Institute of Architects.

Bowie, R., Jahn, A. (2002). The New Directive on the Energy Performance of Buildings; European Commission, Directorate General for Energy \& Transport: Brussels, Belgium.

Buchanan, A., Honey, B. (1994). "Energy and carbon dioxide implications of building construction." Energy and Buildings, 20, 205-217.

Citherlet, S. (2001). Towards the Holistic Assessment of Building Performance Based on an Integrated Simulation Approach; Swiss Federal Institute of Technology EPFL: Lausanne, Switzerland.

CMU. EIO-LCA: Free, Fast, Easy Life Cycle Assessment. Retrieved on March 20, 2011 from http://www.eiolca.net/index.html

Cole, R. J. (1999). "Energy and greenhouse gas emissions associated with the construction of alternative structural systems." Building and Environment, 34, 335-348. 
Consoli, F., Allen, D., Boustead, I., Fava, J., Franklin, W., Jensen, A., Oude, N., Parrish, R., Perriman, R., Postlethwaite, D., Quay, B., Seguin, J., Vigon, B. "Guide Lines for Life-Cycle Assessment." A 'Code of Practice', Society of Environmental Toxicology and Chemistry SETAC, Pensacola, FL, USA.

Emarald architecture case studies in green building, green source magazine, chapter five, offices, McGraw hill companies inc., 2008.

Emmanuel, R. (2004). "Estimating the environmental suitability of wall materials: preliminary results from Sri Lanka". Building and Environment, 39, 1253-1261.

Ge, X., Harfield, T., “The Quality of Data and Data Availability for Property Research.” The 13th Pacific Rim Real Estate Society Conference, Perth, Australia, January 2007.

Gerfen, K. (2005). “Seeing Green.” Architecture, 91(11), 70-73.

Harris, J. D. (1999). "A quantitative approach to the assessment of the environmental impact of building materials." Building and Environment, 34, 751-758.

Huberman, N., Pearlmutter, D. (2008). "A life-cycle energy analysis of building materials in the Negev desert." Energy and Buildings, 40, 837-848.

Jincheng, X., Weichang, H., Xinli, K., \& Tianmin, W. (2001). "Research and development of the object-oriented life cycle assessment database." Materials and Design, 22(2), 101-105.

Junnila, S., Harvath, A. (2003). Life cycle Environmental Effects of an Office Building .J. Infrastruct. Syst. 9,157-167.

Junnila, S., Horvath, A., Guggemos, A. (2006). Life-cycle Assessment of Office Building in Europe and the United States. J. Infrastruct. Syst., 12, 10-17.

Kibert, C. (1994). "Establishing Principles and a model for sustainable construction". CIB, TG 16

Kristin, A., Petersen' B. S. Environmental and economic impacts of substitution between wood products and alternative materials: a review of micro-level analyses from Norway and Sweden. 
LaGrega, M. D., Buckingham, P. L., Evans, J. C., Group, (1994). T.E.R.M. Hazardous Waste Management; McGraw-Hill: Bucknell, CA, USA.

Lippiatt, B.C. (2007). BEES 4.0- Building for Economic and Environmental Sustainability (Technical manual and user guide) National Institute for Standards and Technology. Retrieved from http://www.nist.gov/

Ljungbergg, L.Y. (2007). "Materials selection and design for development of sustainable products”. Materials \& Design, 28(2), 466-479.

Morel, J. C., Mesbah, A., Oggero, M., Walker, P. (2001). Building houses with local materials: Means to drastically reduce the environmental impact of construction. Building and Environment, 36 (10), pp. 1119-1126

National Renewable Energy Laboratory (NREL). (2004). "U.S. LCI Database ProjectUsers Guide". Retrieved from http://www.osti.gov/bridge

Natural Building Technologies (NBT), Building Environmental Impact. Retrieved from http://www.natural-building.co.uk/environmental_impact.html

Nicoletti, G., Notarnicola, B., Tassielli, G. (2002). Comparative life cycle assessment of flooring materials: ceramic versus marble tiles. J. Clean Prod. 10, 283-296.

Raynsford, N. (1999). The UK's approach to sustainable development in construction. Build Res. Inf. 27, 419-423.

Schinas, O. (2007). "Examining the use and application of multi-criteria decision making technique in safety assessment." International Symposium on Maritime Safety, Security and Environmental Protection.

Sonnemann, G., Castells, F., Schuhmacher, M. (2003). "Integrated Life-Cycle and Risk Assessment for Industrial Processes.” Lewis Publishers: Boca Raton, FL, USA.

Svensson, N. (2006). "Environmental relevance and use of energy indicators in environmental management and research." Journal of Cleaner Production, 14, 134-145. 
Thormark, C. A., (2002). Low energy building in a life cycle-its embodied energy, energy need for operation and recycling potential. Building and Environment, 37, 429-435.

Trusty, W. B. (2004). In Life Cycle Assessment: Databases and Sustainable Building, Latin-American Conference on Sustainable Building; The Athena Institute: San Paulo, Brazil.

Trusty, W. B., (2003). "Sustainable Building: A Materials Perspective". Prepared for Canada Mortgage and Housing Corporation Continuing Education Series for Architects.

Trusty, W.B., Meril, J. K. and Norris, G. A. (1998). ATHENA: A LCA Decision Support Tool for the Building Community, Proceedings: Green Building Challenge '98 An International Conference on the Performance Assessment of Buildings. Vancouver, B.C., October $26-28,8 \mathrm{pp}$

United Nations Environment Programme UNEP. (2003). Sustainable Buildingand Construction; Division of Technology, Industry and Economics: Paris, France.

USGBC, (2002). "Building Momentum: National Trends and Prospects for HighPerformance Green Buildings." Report prepared for the US Senate Committee on Environment and Public Works.

USGBC, (2005). U.S. green Building Council, "LEED ${ }^{\circledR}$ for new construction and major renovations", Version 2.2

Xing, S., Xu, Z., Jun, G. (2008). Inventory analysis of LCA on steel and concreteconstruction office buildings. ENB, 40, 1188-1193. 